\title{
Análisis de la visita pública a la Necrópolis Romana de Carmona entre 1885 y 1985
}

\section{Analysis of the public visit to the Roman Necropolis of Carmona between 1885 and 1995}

\author{
Ignacio Rodríguez Temiño \\ Conjunto Arqueológico de Carmona \\ Consejería de Cultura \\ Junta de Andalucía \\ José Ildefonso Ruiz Cecilia \\ Conjunto Arqueológico de Carmona \\ Consejería de Cultura \\ Junta de Andalucía \\ Carmen Mínguez García \\ Universidad Complutense de Madrid
}

\section{RESUMEN}

Inaugurada en 1885, la Necrópolis Romana de Carmona es el primer yacimiento en abrirse a la visita pública en España. Este museo ha prestado durante ciento treinta años un continuo servicio a la investigación arqueológica, la educación, el ocio cultural y el turismo, si bien solo el primero de estos aspectos es conocido. A través del estudio del archivo que posee la institución este trabajo profundiza en esos aspectos en el periodo entre 1885 y 1985 , permitiendo una aproximación no solo al número de visitantes, sino también a sus características demográficas, al impacto de esta institución en el currículo escolar y en el turismo procedente de España y el extranjero, así como a la imagen que el yacimiento dejaba en los visitantes, normalmente muy alejada de las visiones oficiales sobre el patrimonio arqueológico.

\section{SUMMARY}

Inaugurated in 1885, the Roman Necropolis of Carmona was the first archaeological site to be opened to public visitors in Spain. This museum has been paying continuous service to archaeological research, education, leisure and cultural tourism, for the last 130 years, but it is currently only really recognized for its services to archaeological research. By studying the documents between 1885 and 1985 belonging to the institution's archive, this paper explores these issues, allowing not only an approximation of the number of visitors, but their demographic characteristics, the impact of this institution on the school curriculum and tourism from both Spain and abroad, as well as the visitor's views on the site, which are usually far from that maintained by the official archaeology on the archaeological heritage.
PALABRAS CLAVES: Necrópolis Romana de Carmona; álbumes de firmas; archivos históricos; visita pública a yacimientos arqueológicos; turismo; imagen de los yacimientos arqueológicos; museo y escuela.

KEY WORDS: Roman Necropolis of Carmona; guest's books; historical documents; archaeological sites' visitors; tourism; archaeological sites' image; museums and school.

\section{INTRODUCCIÓN}

La bautizada en 1885 como Necrópolis Carmonense, aunque conocida desde casi los inicios de su andadura como Necrópolis Romana de Carmona (en adelante NRC), fue un proyecto cultural pionero en España, nacido al calor del interés por el pasado y la arqueología característicos de las élites burguesas de finales del siglo XIX (Maier Allende 1997 y Beltrán Fortes 2002). Esta precocidad viene referida al hecho de hacer visitable un yacimiento tras su excavación, puesto que ya existían ejemplos de museos de iniciativa pública y colecciones privadas accesibles a los visitantes en Andalucía, años antes de la inauguración de la NRC (López Rodríguez 2010: 203 ss.).

El proyecto consistió básicamente en la excavación de parte de la necrópolis romana occidental de la antigua Carmo (Rada y Delgado 1885: 6-9; Maier 
Allende 1999: 42 ss.), a la par que se adquirían esos terrenos y se adecuaban a la visita pública, completándose la operación con la construcción de un museo de sitio donde exhibir los bienes muebles procedentes de las excavaciones, también el primero levantado en la Península Ibérica (Maier Allende 1999a: 58-66; Gómez Díaz 2006 y Rodríguez Temiño 2010 y 2014a).

Los artífices de esta empresa fueron Juan Fernández López y George E. Bonsor. Del primero de los cuales, farmacéutico y erudito local, se tienen pocos datos biográficos, aparte de los mencionados por De la Rada y Delgado (1885: 83-84). Su producción como aficionado tampoco ha dejado una profunda huella, pasando prácticamente desapercibido para la posteridad (Maier Allende 2004 y Ayarzagüena Sanz y Renero Arrivas 2009), aunque su dedicación a la NRC y a la conservación y valorización del patrimonio arqueológico carmonense está siendo reivindicada recientemente (Ruiz Cecilia et alii 2011, Rodríguez Temiño 2014b). Sobre George E. Bonsor, pintor de origen anglofrancés, y su papel fundamental en el amateurismo arqueológico característico de finales del siglo XIX y el primer tercio del Xx, resulta fundamental la obra de Maier Allende (1999a y 1999b).

Comenzada como una iniciativa privada impulsada por ambos eruditos, poco antes de la muerte de Bonsor fue donada al Estado español en 1930, quien ha mantenido su titularidad hasta su traspaso a la Junta de Andalucía en 1984. La pertenencia a la administración pública supuso para la NRC la pérdida de independencia, ya que a partir de 1938 pasaría a estar subordinada al Museo Arqueológico de Sevilla, situación que se ha mantenido hasta 1992, cuando la comunidad autónoma de Andalucía creó para su gestión una unidad específica, el Conjunto Arqueológico de Carmona, nombre con el que se conoce actualmente a la institución en el ámbito administrativo.

La NRC ha pasado a la bibliografía arqueológica sobre todo por la investigación de los complejos funerarios que alberga (Rada y Delgado 1885; Bonsor 1931; Fernández-Chicarro 1969; Bendala Galán 1976, entre otros), siendo menos conocidos otros aspectos referidos a su gestión como museo. Si bien esta laguna se viene cubriendo para fechas recientes, queda aún por indagar la mayor parte de su existencia como institución museística. Se ha publicado un conjunto de fotos inéditas tomadas entre 1885 y 1930 (Ruiz Cecilia et alii 2011), pero poco más. Sin embargo, el archivo del Conjunto Arqueológico de Carmona (ACAC en lo sucesivo) guarda una apreciable cantidad de documentos que arroja luz sobre temas desconocidos de la gestión museística de usuarios y visitantes entre finales del siglo xıx y la actualidad. Si bien para los últimos treinta o cuarenta años, todas las instituciones análogas al Conjunto Arqueológico de Carmona pueden ofrecer datos y experiencias valorables, esta institución es prácticamente uno de los pocos yacimientos visitables en Europa con posibilidad de suministrar información fiable sobre su gestión desde finales del siglo xıx, ya que la inmensa mayoría comenzó su actividad más tarde.

De entre los documentos relativos a sus visitantes guardados en el ACAC, destacan los álbumes de firmas, cuyo inicio data del mismo día de la inauguración solemne de la visita pública ${ }^{1}$; los partes de trabajos que se remitieron trimestralmente al Ministerio de Educación Nacional entre 1938 y $1975^{2}$, aunque la serie no está completa; las memorias anuales de actividades $^{3}$; las estadísticas de investigadores y visitantes ${ }^{4}$; así como anotaciones dispersas de ventas diarias de entradas, postales y guías, de Juan Fernández López . A ellos deben añadirse otros depósitos documentales, como el de la Biblioteca Municipal de Carmona, con valiosas colecciones de periódicos locales de la época, como La Andalucía (Sevilla), La Revista, El Zurdo, La Sinceridad y La Verdad, todos ellos de Carmona y el último, además, propiedad de Juan Fernández López y de su hermano Manuel.

Estas fuentes aportan datos cuantitativos - sin duda los más afectados por las lagunas y la heterogeneidad documental- e información cualitativa fundamentales para perfilar el papel jugado por la NRC como enclave cultural y educativo en su entorno social próximo que, poco a poco, irá incrementándose conforme las prácticas turísticas y el consumo cultural se extienda a amplias capas de la población. Pero sobre todo este cúmulo informativo permite contrastar determinados asertos teóricos en torno a las prácticas culturales, el turismo o la relación entre la escuela y los museos con la realidad dibujada por los datos, así como también acerca a determinados aspectos poco analizados de la figura de George E. Bonsor, auténtico generador de comunidades de usuarios. Por último, los comentarios libremente dejados por los visitantes ofrecen una idea prístina de la imagen que tienen del yacimiento y, por extensión, del monumento histórico y su función social.

"Libro álbum de firmas 1885-1906", ACAC III.1.3. leg. 1 lib. 4; "Libro álbum de firmas 1906-1922", ACAC III.1.3. leg. 1 lib. 5; "Álbum de firmas 1922-1957", ACAC I.4.4. lib. 24 y "Álbum de firmas 1960-..." ACAC I4.4. lib. 25.

2 "Partes Trimestrales de Trabajo 1938-1975" ACAC I.1.2. leg. 2 .

3 "Memoria Anual de Actividades 1959-1979" ACAC I.1.3. leg. 3 .

"Investigadores y visitantes 1960-1990" ACAC I.1.4. lib. 25 y "Estadísticas visitantes 1975-1990" ACAC I.1.4. leg. 57.

5 "Libro de cargo y data, sueldos trabajadores, entrada visitantes 1887-1903" ACAC III.1.2. leg. 1 lib. 2. 
Con todas esas fuentes documentales se ha construido este trabajo que arroja luz sobre la gestión y el uso dado a una iniciativa pionera en el ámbito cultural a escala europea. Aunque en realidad no resulte fácil separar temáticas, como la visita cultural, el turismo o la educación, por cuanto que carecen de límites claros y sus contenidos se solapan al menos parcialmente, en lo que sigue se explicarán estos aspectos de manera segregada para favorecer su exposición.

\section{LAS FUENTES DE INFORMACIÓN Y SU VA- LIDEZ}

Una vez enumeradas las fuentes documentales conviene detenernos sobre su naturaleza y grado de fiabilidad.

Como ya se ha explicado en la introducción, son tres las series documentales con datos útiles para la cuantificación anual del número de visitantes: los álbumes de firmas, los partes de trabajo y las estadísticas de visitantes e investigadores. Cada una de ellas tiene sus propias peculiaridades que, además, han cambiado a lo largo del tiempo, lo que ha repercutido sobre su grado de fiabilidad. Aunque no sean estrictamente consecutivas en el tiempo, sino que exista solapamiento entre ellas, cada una de las series ha sido usada como fuente principal para diferentes periodos: los álbumes de firma entre 1885 y 1960, los partes entre 1960 y 1977 y, finalmente, las estadísticas entre 1977 y 1985.

Para comprender mejor la necesidad de recurrir a fuentes indirectas durante 1885 y 1960, deben tenerse presente varias circunstancias. En primer lugar, en el periodo en que la NRC era una propiedad privada (1885-1930), su régimen jurídico quedaba al margen de los museos estatales, con lo cual no le era de aplicación la normativa emanada para estos, y por tanto no tenían obligación de llevar la puntual estadística de los visitantes prevista en el artículo 60 del Reglamento general de los Museos regidos por el Cuerpo facultativo de Archiveros, Bibliotecarios y Arqueólogos, aprobado por Real Decreto de 29 de noviembre de 1901.

Bien es verdad que Juan Fernández López llevó un libro con la contabilidad de los ingresos y gastos donde se recoge el número de entradas vendidas a partir de 1887, pero no deja constancia del número de personas que accedían gratuitamente a las instalaciones que sabemos, por contrastar los datos suministrados por ambos documentos, debieron suponer un nutrido porcentaje.

En segundo lugar, entre 1930 y 1940, la pertenencia al Estado de la NRC no supuso la asignación de personal facultativo para su dirección, sino que esta se encomendó de forma honoraria a Juan Rodríguez Jaldón, profesor de dibujo en Carmona, quien se interesó por las pinturas murales de los complejos romanos (Fernández Gómez y Baceiredo Rodríguez 2001), pero que no dejó ningún documento de carácter administrativo. Aunque fue en 1938 cuando se produjo la anexión de facto de la NRC al Museo Arqueológico de Sevilla, esta dependencia se formalizó mediante Orden de 28 de febrero de 1941. Sin embargo, por los motivos que fuesen, parece que Juan Lafita, director entonces del Museo Arqueológico de Sevilla, fue remiso a cumplir con sus obligaciones con respecto a la recopilación de estadísticas de la Necrópolis. Los principales documentos referidos a esa época custodiados en el ACAC son las quejas emitidas anualmente desde el Servicio de Inspección de Museos Arqueológicos ante la absoluta falta de cumplimiento en el envío de estadísticas de visitantes a ese centro directivo, desde el museo de la NRC. Tal actitud es reprochada por el director general de Bellas Artes que pone al museo de la NRC como deplorable ejemplo de incumplimiento de obligaciones. Por otra parte, los pocos años en que los partes de trabajo están completos, el número de visitantes se acerca bastante al obtenido mediante el conteo de las firmas.

Con la llegada a la dirección del Museo Arqueológico de Sevilla de Concepción Fernández-Chicarro en 1959, se normaliza el tráfico de documentación administrativa. Esta normalización coincide con una creciente disminución en el número de firmantes en los álbumes, motivo por el que entre 1960 y 1977, las cifras se han tomado de los partes. Entre 1977 (último año con parte) y 1985 nos hemos dirigido a los libros de estadísticas de visitantes e investigadores, cuya llevanza comenzó en 1960 y fueron la fuente de la que se extrajeron los datos de los partes trimestrales.

Otro aspecto no menor acerca de los álbumes de firmas ha sido dilucidar si el número de firmantes refleja grosso modo el de visitantes. No cabe, por supuesto, una respuesta categórica a esta cuestión, aunque por ciertos indicios es plausible pensar que, durante la etapa en que han aportado el principal caudal de datos (1885-1960), esta relación fue bastante equivalente.

En primer lugar, para Juan Fernández y George E. Bonsor la finalidad de los álbumes, reflejada en la inscripción manuscrita en el primero de ellos y reproducida en un apéndice al Reglamento de la Sociedad Arqueológica de Carmona ([Fernández López] 1887: 18$)^{6}$, aparece clara: servir como soporte para

\footnotetext{
6 "En la ciudad de Carmona (...), se reunieron en el Campo nombrado de las Canteras y que desde este día se titulará
} 
perpetuar la admiración y elogio que la contemplación de las excavaciones debía levantar en los visitantes. Se constata, además, un mantenimiento casi contínuo de estos testimonios: ambos cuidan, leen y anotan en el álbum? . Por ejemplo, añaden en una "g" a quienes posiblemente accedieron de forma gratuita al recinto, reflejan la fecha del fallecimiento junto a la firma de alguien conocido, o signos tales como "=" o "+", cuyo significado se nos escapa. Bonsor deja asimismo anotaciones de su puño y letra anunciando que se va de viaje o que vuelve, junto a otras que manifiestan el control hecho sobre el número de visitantes, del tipo "El 14 de febrero [de 1894] visitaron la $\mathrm{Ne}$ crópolis 2 personas que no firmaron". Por su parte, Juan Fernández, lee las anotaciones dejadas por los visitantes y no duda en comentarlas cuando así lo considera necesario. De igual forma, en las actas de la Sociedad Arqueológica de Carmona, de la que fue secretario (Maier Allende 1997), dejó párrafos dedicados a comentar visitas ilustres a la NRC ${ }^{8}$.

Como ya hemos explicado, se han realizado chequeos entre los datos aportados por los álbumes y los partes trimestrales de trabajos y los resultados son casi coincidentes hasta la década de los sesenta. No obstante, a partir de 1964 se observa un cambio porque el álbum debió de retirarse de la recepción del museo y sacarse solo para la firma de personajes y arqueólogos ilustres.

El uso de los álbumes de firmas ha permitido distinguir entre hombres y mujeres, así como entre nacionales españoles y extranjeros, salvo cuando las firmas eran ilegibles, pero en los informes trimestrales no aparece la desagregación por género, con lo cual esta solo ha podido establecerse hasta la década de los sesenta. Mejor suerte ha habido con los grupos de visitantes ya que en los álbumes no es infrecuente su delimitación, ya sea mediante agrupación bajo un rótulo o una anotación sobre la naturaleza del grupo $\mathrm{y}$, en ocasiones, también la procedencia, encerrada entre líneas o llaves o aislándose del resto de los fir-

Necrópolis Carmonense (propiedad de los referidos Fernández y Bonsor) los señores que al margen se anotan; y rogados para que examinasen los trabajos de excavación hechos en el nombrado Campo (...). Unánimemente convinieron en que la empresa esta llevada a término con inteligencia y acierto y con una perseverancia extraordinaria y digna de los mayores elogios, siendo tan plausible la idea, que dejará alto ejemplo que imitar a cuantos estimen las glorias del país (...)".

${ }^{7}$ Es bien conocido que Bonsor, que vivió casi veinte años en la casa aneja al museo de sitio, gustaba de llevar anotaciones en cuadernos y hojas sueltas sobre quienes le visitaban, tanto durante esta época como más adelante en su residencia del castillo de Mairena del Alcor (Peñalver Simó [coord.] 2010: 40-160).

8 "Libro de actas de la Sociedad Arqueológica de Carmona. 1893-1909”, ACAC III.2.1. Leg. 2, lib. 7. mantes. Tampoco resulta raro que pueda establecerse la naturaleza familiar de algunos de ellos, evidenciada por la repetición de apellidos. En el "Libro de cargo y data..." ya mencionado, también se recogen datos que permiten inferir el tamaño de los grupos, corroborado por agrupaciones de firmas realizadas en los propios álbumes, e incluso las visitas individuales.

En cuanto a las fechas, indicar que sobre las anualidades no hay mayor problema en su identificación, aunque el hábito de anotar la fecha de la visita tiene distinto ritmo según la procedencia de los visitantes. Mientras que desde muy temprano los extranjeros suelen añadirla junto a la firma, así como la procedencia, los visitantes españoles resultan ser más reacios a escribir esas indicaciones, no siendo frecuentes hasta la década de los veinte del pasado siglo.

\section{LA VISITA CULTURAL Y CIENTÍFICA}

Observando las figuras $1 \mathrm{a}$ y $1 \mathrm{~b}$ resalta el bajo monto de visitantes hasta la segunda mitad de la década de los cincuenta. Durante el primer periodo (1885-1956), el número de visitantes anuales no llega a 300 hasta el comienzo de la década de los veinte, experimentando un repunte puntual en el entorno temporal de la Exposición Iberoamericana de 1929, para caer durante la guerra civil, si bien sorprende la presencia de visitantes y recuento de los mismos en plena contienda (1936 y 1938) ${ }^{9}$. A comienzo de los cincuenta, el número de personas que accedieron al recinto se situaba en guarismos próximos a los que había tenido a finales de la centuria anterior. El remonte se notará durante la segunda mitad de los cincuenta, aunque la gráfica experimenta una caída por falta de datos para 1957 y 1958, así como porque los de 1959 están solo referidos al último trimestre. En la década siguiente la cifra se sitúa por encima de 4.500 personas anuales, multiplicándose por dos a finales de los sesenta. En 1972 los valores están por encima de las 10.000 personas para caer por efecto de la crisis dos años más tarde, remontando en línea ascendente hasta los 17.468 registrados en 1985, último año de este estudio ${ }^{10}$.

Aunque sin duda los datos expuestos en los mencionados gráficos son, de por sí, una novedad en el panorama bibliográfico de la historiografía de la ar-

\footnotetext{
${ }^{9}$ En esos momentos la única persona con que contaba la institución era un guarda, Fernando Escamilla Ortiz, posiblemente contratado por el Ayuntamiento, aunque llevaba con Fernández López y Bonsor desde 1911. Más adelante volveremos sobre él y su función como guía.

${ }^{10}$ En la última década las cifras de visitantes se mantienen estables en torno a los 32.000 (Mínguez et alii 2014).
} 


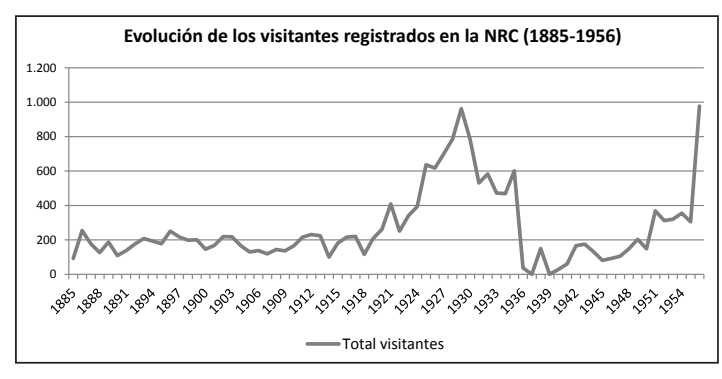

Figura 1a. Evolución de los visitantes a la NRC entre 1885 y 1956.

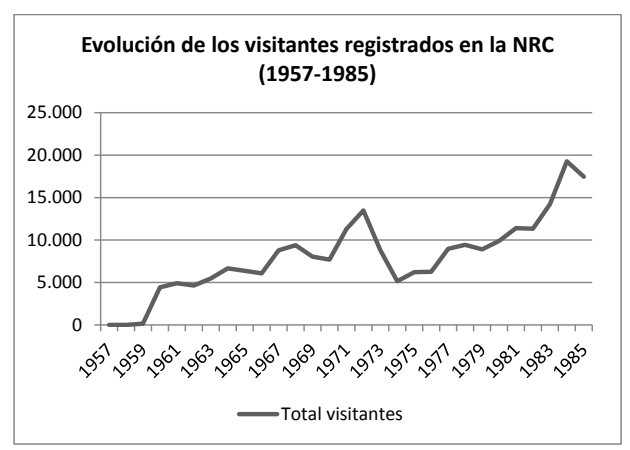

Figura 1b. Evolución de los visitantes a la NRC entre 1957 y 1985.

queología española y de la gestión del patrimonio arqueológico, resulta evidente que el esfuerzo desplegado amerita culminarse con su adecuada interpretación para evaluar su significado y aportación al estado actual de los conocimientos en esas materias.

Conviene ahora hacer una ligera alusión a la distribución de hombres y mujeres que visitaron la NRC. Entre 1885 y 1935, periodo en que los conteos de visitantes se han basado en los álbumes de firmas, la proporción entre sexos es de 1 a 3 , a favor de los hombres. El comportamiento de la visita femenina está asociado a grupos familiares (o posiblemente amigos). Destaca el alto porcentaje de mujeres en el grupo de usuarios de la NRC generado en torno a la figura de Bonsor, quienes además visitan la NRC acompañando a personas de fuera, con una función marcadamente protocolaria. En la segunda década del siglo $\mathrm{xx}$, comienzan a ser más frecuentes grupos de mujeres que visitan la NRC sin compañía de hombres, en alguna ocasión incluso indicaron la procedencia y el día de la semana en que se realizó la excursión. Entre 1936 y 1985 el porcentaje de firmas femeninas (que no puede asimilarse siempre al de visitantes, como ya se ha indicado) experimenta un incremento al alza tanto por la importancia del turismo, como por la visita de escolares.
En este estudio distinguiremos entre visitantes y usuarios, en atención a la frecuencia con que han accedido a la misma y a la mayor amplitud de motivaciones para hacerlo de los segundos frente a los primeros (Castañeda Alañón 2001-2002), ya que ello nos dará pie para entrar en otros aspectos relativos a la pluralidad de funciones que ha jugado la NRC, sobre todo en sus primeros tiempos, a la comunidad de usuarios asiduos generada en torno a ella y a sus primigenios dueños.

\subsection{INICIALES VISITANTES Y USUARIOS}

El inicio de la visita cultural a la NRC se puede situar en el denominado acto de inauguración de la $\mathrm{NRC}$, que en realidad fue una apretada jornada vertebrada por una visita guiada por Fernández López y Bonsor a los complejos funerarios excavados o redescubiertos para la ocasión (Rada y Delgado 1885: 7-10), al que sucedieron otras actividades de carácter festivo y cultural ${ }^{11}$. Al término de las cuales los asistentes firmaron un acta en un libro, dando comienzo al primero de los álbumes de firmas. Los 29 invitados, elegidos por los anfitriones, procedían del ámbito sociológico en que se movían ambos. Además de los miembros de la Sociedad Arqueológica de Carmona (en adelante SAC), creada dos días antes, asistió "un gran número de personas de reconocida ilustración y entusiastas de los estudios históricos, representantes de las Reales Academias de la Historia y San Fernando, delegados de la Ilustrísima Comisión de Monumentos Históricos y Artísticos de la provincia, de la Excma. Diputación Provincial, de Municipio de Sevilla y las autoridades de esta ciudad [Carmona]" ([Fernández López] 1887: 17). Aunque no se relaciona en la Memoria de la Sociedad Arqueológica de Carmona, existe constancia de la invitación formal a Manuel Sales y Ferré, catedrático de la Universidad de Sevilla, así como del vicecónsul británico en Sevilla y otro súbdito británico residente en la capital, Srs. Johnston y McDougall, que firmaron más tarde, en su primera visita, en el hueco dejado al efecto.

Para esta ocasión se diseñó una ruta y un discurso sobre la NRC, al tiempo que se tomó conciencia de la necesidad de establecer un control, por lo que en la página siguiente del álbum, bajo el rótulo "Visitantes 1885", comenzó un reguero de firmas que sin sustanciales soluciones de continuidad ha llegado hasta hoy (Fig. 2).

\footnotetext{
${ }^{11}$ La prensa local y sevillana, invitada al evento, dio cumplida cuenta de la sucesión de actos celebrados ese día (Ruiz Cecilia et alii: 15-34).
} 


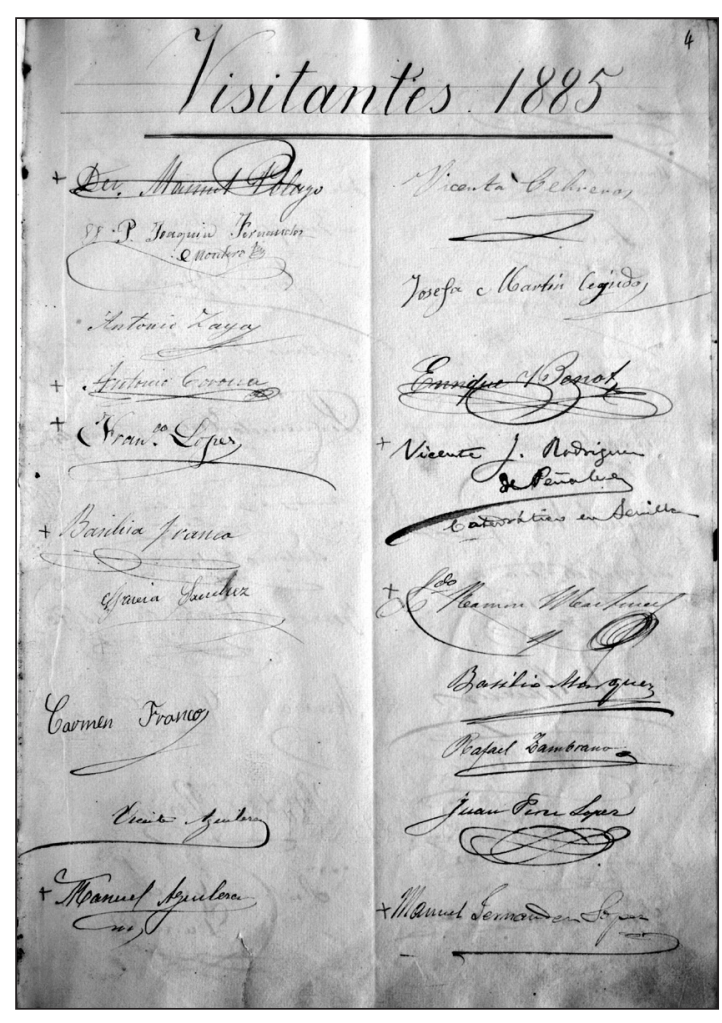

Figura 2. Álbum de firmas de la NRC.

El acceso a la NRC tenía el precio de una peseta, aunque era gratis para quienes fuesen acompañados de algún socio de la SAC cuando, además, asistiesen a una asamblea extraordinaria de la misma, según recoge el artículo 11 de su Reglamento. Si el alto porcentaje de analfabetismo registrado en España (y en la provincia de Sevilla ${ }^{12}$ ) en esa época no suponía ya una barrera infranqueable para el acceso del pueblo llano a la NCR, este cargo en la entrada sí que debió resultar disuasorio, teniendo presente que un peón en la NRC cobraba un sueldo de 46,50 Pts en 1887 por 31 días de trabajo ${ }^{13}$. Para la mentalidad del momento los destinatarios eran individuos de las clases acomodadas (Fig. 3), sin especial interés en facilitar la visita a las populares.

A la vista de los datos tampoco cabe decir que el acceso fuese masivo. Durante los quince siguientes

\footnotetext{
${ }^{12}$ De acuerdo al censo de 1877 Carmona tenía una población de 17349 personas y una tasa de analfabetismo (general para toda la provincia) del $73,00 \%$, con un porcentaje mayor de mujeres que hombres (Gómez Zarzuela 1885: 110-114). Ulteriores censos rebajan este porcentaje de analfabetismo al $64,9 \%$ en 1890 y al 56,6 en 1920, pero en cualquier caso muy altos con respecto a los países noreuropeos (Ramírez Olid 1999: 552 ss.).

${ }^{13}$ Datos sacados del "Libro de cargo y data, sueldos trabajadores, entrada visitantes 1887-1903” ACAC III.1.2. leg. 1 lib. 2.
}

años el promedio de visitantes anuales es de 171 personas, para aumentar a 420 hasta la guerra civil y ascender a 9020 entre 1964 y 1985. La visita suele espaciarse a lo largo del año, aunque existe una concentración en los meses de primavera, comienzos del verano y otoño.

A pesar de la parquedad de datos con los que contamos, es posible establecer algunas pautas de comportamiento en la visita. A través del "Libro de cargo y data, sueldos trabajadores, entrada visitantes 1887-1903" en que vienen reflejados el número de entradas vendidas por día, se aprecia que, en los primeros tiempos, no resultaba infrecuente la visita individual, aunque lo más corriente son los grupos familiares compuestos de entre cuatro y siete personas, aunque también los haya mucho más numerosos. La identificación no es siempre posible, pero durante todo el siglo xIX y los primeros años del xx se advierte un porcentaje no despreciable de personas con apellidos frecuentes en Carmona, normalmente ramas secundarias de las grandes familias burguesas o de la nobleza enraizadas en la localidad (Lasso de Vega, Quintanillas, Domínguez, Vélez-Bracho, Briones, De la Vega Campanario, De la Vera y Arboleya o Ponce de León, la marquesa de Donadío, la vizcondesa de Dos Puentes, entre otros), junto a otras pertenecientes a la mesocracia local o de localidades cercanas, como Mairena del Alcor o Sevilla (Franco, Buzón, Acal, Astolfi o Aguilera y Simó y López de Haro, capitán de la Guardia Civil residente en Mairena del Alcor y padre de la segunda mujer de George E. Bonsor). Resalta del comportamiento de estas personas su reiterada visita (dos o tres veces por año, lo que las convierte en usuarios), pero no necesariamente todas juntas, sino que parecen acompañar a otras, ya que en los grupos solo se identifican uno, dos o tres de estos apellidos, el resto resulta desconocido

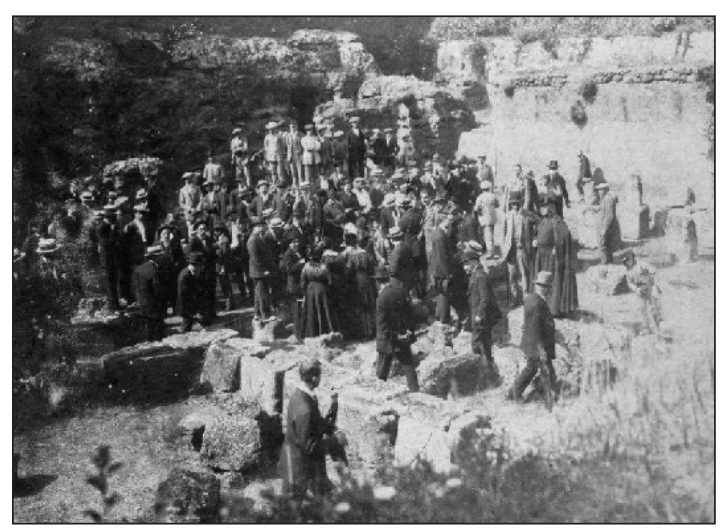

Figura 3. Visita de grupo a la tumba de Servilia (Archivo General de Andalucía). 
y no vuelve a aparecer en los álbumes de firma. En ocasiones, esta reiteración queda reflejada en algún comentario bajo la firma, del tipo "Es la segunda vez que vengo y espero que no [sea] la última", o más escuetas: "2 visita".

A pesar de lo que podría presagiar la previsión de su Reglamento, el papel jugado por los miembros de la SAC en la repetición de las visitas no resulta especialmente relevante. Solo José Vega Peláez firma con cierta frecuencia y siempre acompañado de otras personas, lo que podría sugerir que tal frecuencia se debiese a una labor de guía de visitantes. Aspecto sobre el que volveremos a incidir más abajo.

Otro hecho llamativo en torno a estos grupos de usuarios es el cambio de centralidad de Juan Fernández López a George E. Bonsor y la reacción del primero. Reiterando que la NRC ha estado bajo la égida de Fernández López ab initio y que en los invitados a la inauguración se advierte que son fundamentalmente una proyección de su esfera de socialización, no puede negarse que el influjo de Bonsor se hizo sentir más pronto que tarde y que los integrantes de la comunidad de usuarios durante finales de la década de los ochenta y los noventa están nucleados por él. No nos referimos a los arqueólogos nacionales o extranjeros que vienen a verla, habida cuenta de la notoriedad en el ámbito de la investigación arqueológica de Bonsor, sino a las relaciones sociales a escala local. Muchas de esas personas que firman en el álbum más que interés por ver las ruinas vienen a visitarlo a él, porque vivió en una casa aneja al museo hasta 1907, o a participar en diversos eventos organizados por él en la NRC, como el jubileo celebrado el 22 de junio de 1897 en honor de S. M. la reina Victoria (La Andalucía 26 de junio de 1897). El protagonismo social de Bonsor, al menos en el ámbito de la NRC, eclipsó la figura de Fernández López, quien solo de forma ocasional, cuando acompaña a alguna visita distinguida, firma en el libro después de 1887 o, cuando lo hace, como con ocasión del mencionado jubileo, apostilla señalando bajo su firma su condición de "Copropietario de la Necrópolis Romana".

Cuando en 1907 Bonsor fija su residencia en el castillo de Mairena del Alcor, las visitas de este grupo serán más esporádicas, aunque él y su familia vendrán en alguna ocasión a la Necrópolis. El grupo de amistades personales generado en torno a la NRC tampoco aparece en el libro de firmas que Bonsor llevó en su castillo ${ }^{14}$, donde las coincidencias con los álbumes de la NRC se limitan a las familias de

14 "Libro de firmas" AGA. Fondo Bonsor, leg. 6 p. 1 (Cruces Blanco [dir.] 1991: 20). sus sucesivas esposas (Trigueros, Simó y López de Haro) y a personas de ámbito académico.

\subsection{LA EXPANSIÓN DE LA VISITA}

Tanto las excavaciones en la NRC como la inauguración, e incluso la vida de la SAC, fueron objeto de abundante seguimiento periodístico. The Times, The Morning Post, El Liberal (Madrid), La Andalucía Moderna ${ }^{15}$, El Universal, El Orden o El Posibilista (todos ellos de Sevilla), amén de un amplio número de periódicos locales de Osuna, Écija y otras poblaciones del entorno, dieron cuenta de los distintos avatares por los que pasó la NRC durante sus primeros años de vida. Ese interés también sirvió como publicidad atrayendo nuevos visitantes. No obstante, resulta muy revelador que personas como Francisco Rodríguez Marín, quien tuvo un papel destacadísimo en la vida cultural y educativa de la cercana Osuna, visite la NRC mientras vivió en Sevilla, donde frecuentó al círculo ateneísta (Ramírez Olid 1999), y no cuando residía en Osuna.

Aunque no hayamos podido consultar los padrones municipales de la época de todas esas localidades, las diferentes ediciones de la Guía de Sevilla y su provincia (1885-1897), así como el Diccionario de escritores, maestros y oradores (Méndez Bejarano 1989), recogen listados ordenados alfabéticamente y por profesiones, de los vecinos que ejercen cargos públicos o profesionales liberales en Sevilla, e incluso los directores de escuelas públicas o privadas, con lo cual nos ha sido posible realizar un chequeo entre la base de datos de los visitantes y estos listados. Sin embargo, si se exceptúan las personas vinculadas a instituciones, como la Universidad o la Comisión de Monumentos o quienes son reputados por poseer "colecciones de antigüedades", las coincidencias son mínimas y no necesariamente mayores entre quienes están en la cúspide de la pirámide social (nobles, altos cargos de la administración, jueces, médicos, etcétera ${ }^{16}$ ) que las concordancias con otros apellidos

\footnotetext{
${ }^{15}$ José María Tubino Montesinos, director de La Andalucía Moderna, fue un asiduo visitante de la NRC, a la que dedicó en muchas ocasiones espacio para comentar las novedades que acontecían en ella. Otros muchos periodistas pasarán por la NRC dejando constancia de ello, aunque suelen venir como visitantes y no como periodistas, como es el caso del periodista y literato catalán Andrés Matosés, Corzuelo, quien estuvo en 1887 y nunca firmó nada sobre la NRC.

${ }^{16}$ Estos suelen hacer expresa mención de su título, profesión o cargo ("Gobernador Civil" o "Juez de la Audiencia", "Catedrático de Sevilla", "Condesa de Casa Galindo", "Marqués del Saltillo" o "Conde de Rodezno", por ejemplo) o de la presidencia de una asociación profesional.
} 
de escalones más bajos de esa pirámide, por ejemplo los etiquetados como "De la rama del comercio".

Dentro de los grupos auto-identificados, resalta el de guardias civiles, que periódicamente firman en pareja. Cabría pensar en que fuesen mandados por Ángel Simó para cumplimentar algún servicio, pero resulta curioso que no solo firmen en pareja, sino que además también lo hacen en grupos, con sus mujeres. Es decir, que conocida la NRC por motivos del servicio, posiblemente después acceden a ella con sus familias en el tiempo de ocio. Esta visita de miembros del benemérito instituto fue frecuente entre la década de los noventa del siglo xix y la de los veinte de la centuria siguiente, pero se agotó en los años siguientes.

Debido a su creciente notoriedad entre propios y extraños, la NRC se convirtió en uno de los hitos de Carmona y su visita un acto imprescindible en el agasajo a quienes venían a esta localidad por otros motivos. Eso ocurre con las misiones y visitas pastorales que tanto predicadores como miembros de la jerarquía eclesiástica realizan al arciprestazgo de Carmona (Ruiz Sánchez 2009). En todos los casos, se lleva a cabo una gira a la Necrópolis, con obligada firma en el libro, donde quien encabeza la comitiva suele dejar alguna oportuna anotación aclarando el motivo de su visita a la población ${ }^{17}$, así como alguna frase de tono trascendente ("El Arte para el hombre y el hombre para Dios", anotó Rafael González, presbítero de misión en Carmona en 1902).

Este fenómeno de enseñar la Necrópolis en el curso de una visita a Carmona ha sido una constante que llega a la actualidad. Por la institución han pasado dejando su firma los infantes Alfonso de Orleans y Borbón, Carlos de Borbón y Rainiero de Borbón, que estuvieron en 1915; Carmen Polo, esposa del general Franco, en 1967, y el ex presidente de EEUU Jimmy Carter y su esposa Rosalynn en 1997, únicos dignatarios que anotaron además una frase amable agradeciendo las atenciones recibidas durante la visita: "This is one of the most interesting places we have seen! Muchas gracias".

Sin lugar a dudas el grupo más conspicuo de visitantes es el segmento caracterizado por poseer un capital escolar alto. Este amplio grupo podría, a su vez, subdividirse en, al menos, dos conjuntos en función del grado de especialidad con respecto a la temática de la NRC. Por un lado, distinguiremos quienes poseen una vinculación profesional con la arqueología, el patrimonio histórico o los museos,

17 "En pastoral visita", dejó escrito Fr. Ceferino Cándido González, cuando la visitó en mayo de 1888, junto a un nutrido séquito de autoridades y personajes locales. incluyendo también en esta categoría a los cargos de las administraciones culturales, ya que en el periodo objeto de estudio en este trabajo era frecuente que los responsables públicos fuesen reclutados entre profesores universitarios. Por otro, aquellas personas que entran en lo que podría denominarse como "mundo de la cultura", ya tengan vinculación universitaria o no.

Quedan excluidas de este apartado las visitas organizadas como complemento a la impartición de asignaturas universitarias, excursiones universitarias o viajes "fin de curso", por cuanto que este modelo de visitas se tratará bajo el epígrafe dedicado a la NRC y el aula.

En el heterogéneo grupo de intelectuales, vinculados al mundo de la cultura sensu lato, destacan sobre todo artistas, escritores y periodistas o políticos residentes en Carmona, como el pintor José Arpa, el diputado Lorenzo Domínguez de la Haza, el conde de Rodezno, cuyo hijo donará al Estado el anfiteatro; o en Sevilla, José de Velilla y su hermana Mercedes; José Gestoso, que fue vicepresidente de la Comisión de Monumentos entre 1903 y 1917 (López Rodríguez 2010: 138-164), Enrique García del Mazo, médico dermatólogo y fundador de la Sociedad Española de Dermatología y Silfigrafía, o el periodista Francisco Peris Mencheta. A ellos se unió un elenco procedente de todo el territorio nacional, como Vicente Blasco Ibáñez, Rodrigo Soriano Barroeta-Aldamar, Alejandro Lerroux (1902), Lucas Mallada (1905), Aníbal González (1911), Manuel Delgado Brakenbury (1916), Josep Sureda i Blanes (1918), Pedro Salinas (1925), José Francos Rodríguez y Manuel de Falla (ambos en 1930), Julián Otamendi y Jorge Guillén (1931), José Hernández Díaz (1932), José Jiménez Ferrero (1940) o el cantante Jorge Sepúlveda (1951). Sin olvidar a extranjeros de la talla de W. Somerset Maugham (1898), Edmond Rostand o Grace Frick y Marguerite Yourcenar (1960), quienes además dejaron amables comentarios en defensa del joven guía que les enseñó la NRC.

\subsection{LA VISITA EXPERTA}

El que podría considerarse como público experto organizó sus visitas tanto de forma colectiva, normalmente en el seno de asociaciones, como sobre todo de manera individualizada, es decir con pequeños grupos, de dos o tres personas, compuestos por familiares, amigos o colegas. El éxito de la primera reunión, llamada acto de inauguración, animó a los convocantes a repetir la experiencia un año más tarde, el 6 de junio de 1886 ([Fernández López y Bonsor] 1889), para la que de nuevo concitaron la presencia 
de académicos, socios de la SAC, profesores, personas interesadas y políticos ${ }^{18}$. Gracias a esas iniciativas la NRC fue visitada por académicos y correspondientes desde fechas muy tempranas, como Juan de Dios de la Rada y Delgado, Celestino Pujol y Camps, Adolfo Fernández Casanova, Francisco de Asís de Vera, correspondiente en Cádiz de la Real Academia de San Fernando, o Luis Martínez Kléiser, individuo de varias reales academias.

Entre quienes se acercaron a conocer las excavaciones de forma particular, ignorando si fueron o no invitados de manera específica, destacan en los primeros tiempos (entre 1885 y 1887) Antonio Machado y Núñez, Giner de los Ríos o Manuel Bartolomé Cossío, estos últimos los dos primeros directores de la Institución Libre de Enseñanza.

Enraizando con el valor dado por el krausismo y la Institución Libre de Enseñanza al excursionismo como forma de acercamiento a la realidad y al patrimonio arqueológico, dentro del compromiso regeneracionista de la institución que no solo competían al mundo de la enseñanza reglada (Ortega Cantero 1984), destaca la figura de quien fuese el primer impulsor de este excursionismo a la NRC, Manuel Sales y Ferré (Beltrán Fortes 2004).

En efecto, ya en 1883, Sales y Ferré se interesó por ver el desarrollo de las excavaciones junto a José Álvarez de los Corrales, empleado (Gómez Zarzuela 1885: 440) y Siro García del Mazo, propietario de una academia preparatoria para el acceso a la función pública (Gómez Zarzuela 1885: 300), ambos repetidores en las posteriores excursiones organizadas por el Ateneo y Sociedad de Excursiones de Sevilla. En este primer viaje llegaron a Carmona en el tren de la Vega a las 8,30 horas, donde fueron recibidos por George E. Bonsor y los hermanos Fernández López. Desde allí giraron visita a las excavaciones, la puerta de Sevilla y el alcázar de Arriba. El propio Sales y Ferré publicó una crónica sobre esta excursión en El Posibilista (19/04/1883). Dos pasajes reclaman poderosamente la atención de ese texto: el primero, la preocupación por la pérdida de complejos funerarios y ajuares acaecida en años anteriores, confiando en que los nuevos responsables de las excavaciones, "que con algunos de sus amigos han formado una junta para costear los gastos que ocasione su exploración o conservación", recojan todos los materiales en una colección donde pueda estudiarlas el viajero. El segundo, el hecho de que Bonsor captara todo su interés,

\footnotetext{
${ }^{18}$ El recuento de los invitados y el desarrollo de la jornada fue objeto de una detallada crónica en La Andalucía Moderna (08/06/1886), reproducido literalmente en Memorias de la Sociedad Arqueológica de Carmona (1887), páginas 33 a 38.
}

convirtiéndole en el interlocutor de los locales durante la visita, mientras que los hermanos Fernández López quedan relegados a un segundo plano, hasta el punto de equivocar sus nombres y apellidos.

Sales y Ferré siguió visitando la NRC, aunque excusase su participación en los actos de inauguración en 1885 , y fue durante una de esas excursiones, concretamente en noviembre de 1886, cuando surgió la idea de fundar el Ateneo y Sociedad de Excursiones de Sevilla. La institución nació el 6 de mayo de 1887 (Sales y Ferré 1887: 15 ss.), y apenas un mes más tarde vuelven a la NRC dejando expresa constancia del evento: "En expedición organizada por el Ateneo y Sociedad de Excursiones de Sevilla, visitaron este museo y Necrópolis romana de esta histórica ciudad de Carmona, en 5 de Junio de 1887, dirigidos por el Sr. D. Manuel Sales y Ferré...".

En esta ocasión dejaron su autógrafo personalidades como Cano Cueto, individuo de la Real Academia Sevillana de Buenas Letras y director del Ateneo, Feliciano Candau, Carlos Cañal, Joaquín Hazañas y la Rúa, Antonio de las Barras, Javier Sánchez-Dalp o Luis Montoto y Rautentrauch, que conforman un nutrido grupo no solo de historiadores, discípulos de Sales y Ferré y profesores de la Universidad, sino también de intelectuales de la Sevilla finisecular (Beltrán Fortes 2002 y Maier Allende 2002). Sus anuales visitas a la NRC se prolongarán hasta finales de la primera década del siglo xx.

Concretamente Joaquín Hazañas no solo fue un asiduo visitante con grupos, sino que procuraba organizar estas excursiones con bastante antelación, pidiendo a los miembros de la SAC que hiciese el favor de buscar acomodo para el almuerzo así como la organización de una gira por la NRC y el resto de monumentos de la ciudad, entre los que destaca la iglesia de Santa María y las puertas de Sevilla y Córdoba $^{19}$. La potencialidad que presentaba Carmona para la visita cultural y turística contrastaba con sus posibilidades reales, para desesperación de personas conscientes de la pérdida de todo tipo de oportunidades que conllevaba, como Juan Fernández López, que quiso implicar a la Comisión de Monumentos Históricos de Sevilla en la gestión de una apertura para que los visitantes pudiesen acceder a la Puerta de Sevilla, lo que finalmente no logró (Rodríguez Temiño 2014b).

A partir de 1888, Bonsor comienza una nueva etapa de exploraciones arqueológicas, al margen del 
estrecho círculo de la SAC (Maier Allende 1999a: 91-132), que le pone en contacto con arqueólogos extranjeros, algunos de los cuales aprovecharon su estancia en la provincia de Sevilla para visitar la NRC. Williams R. Smith, J. F. Mckey y Arthur E. Shipley, del Corpus Christi College de la Universidad de Cambridge, institución de la que Bonsor interesó apoyo para la realización de la prospección arqueológica del Guadalquivir (Maier Allende 1999a: 93), o Jules Richard, de la Société des Antiquaries de L'Ouest, quien además realizó una extensa reseña sobre los descubrimientos de la Necrópolis (Richard 1889), se encuentran entre los iniciales visitantes desplazados de sus localidades de residencia para visitar a Bonsor. A ellos hay que sumar los arqueólogos franceses que trabajaban ya en España, sobre todo Arthur Engel y Pierre Paris, aunque de este último no hemos podido localizar su firma, nos consta que visitó la NRC, sobre la que, además, incluyó un capítulo en su obra Promenades... (Paris 1910: 107 ss.). En todo caso, Engel sí fue un asiduo visitante de la NRC donde además pasó temporadas residiendo, a partir de 1889, aunque por la relación hecha en el periódico La Andalucía Moderna (08/06/1886) de las personas invitadas a la visita realizada en 1886 a la NRC, es sabido que ya entonces estuvo allí. Además, llevará a la NRC a otros arqueólogos que trabajaban con él en diferentes yacimientos sevillanos, sobre todo Itálica, como Aurelio Gali Lassaleta e incluso a Archer M. Huntington en 1898 (Álamo Martínez 2009), quien mantenía relaciones comerciales con George E. Bonsor, interesado este en vender su colección de objetos prerromanos a la Hispanic Society of America (Maier Allende 1999b: 139 ss. y Maier Allende 2009). También encontramos firmas de Andrés Parladé, Antonio Blázquez, Manuel Gómez Moreno, Ricardo Velázquez Bosco, Adrien de Mortillet, el Marqués de Cerralbo, Cayetano de Mergelina, Hugo Obermaier, Raymond Thouvenot y Anne Jourdan (de la Casa de Velázquez), así como otras personas que jugarían un papel importante en el futuro de la NCR, como Diego Angulo Íñiguez y Juan Lafita, entre otras menos conocidas, durante el periodo en que la NRC fue privada.

Pasada la guerra civil, la NRC comienza poco a poco a entrar de nuevo en los circuitos de visitas de los arqueólogos, Juan de Mata Carriazo, Antonio García y Bellido, Francisco Collantes de Terán, José María Blázquez o Concepción Fernández Chicarro (Fig. 4), son nombres frecuentes desde finales de la década de los cuarenta, junto a miembros del Instituto Arqueológico Alemán de Madrid o de la Bryant Foundation, en visitas siempre acompañadas de la directora del Museo Arqueológico de Sevilla y de la NRC. Conforme la firma en los álbumes se restrinja a personalidades en visitas institucionales, este será el tenor de los últimos años analizados. Entre los responsables públicos que frecuentan la NRC en esos años destacan Gratiniano Nieto y Manuel Fernández-Miranda.

A juzgar por la lista de nombres desplegada en los párrafos anteriores, no exhaustiva pero sí bastante

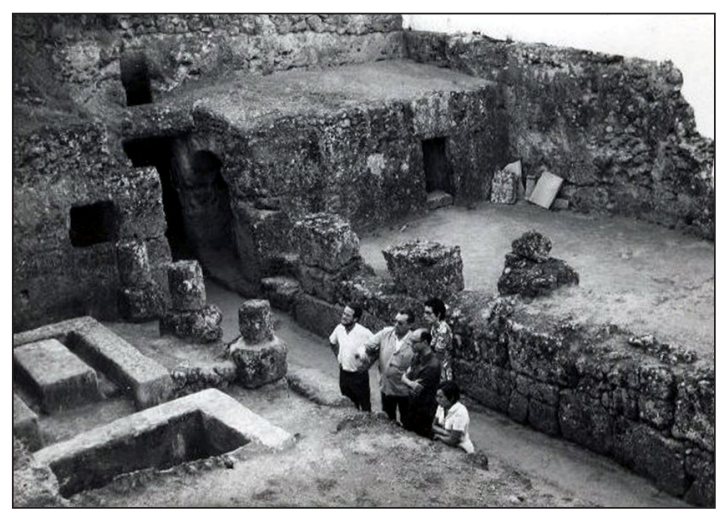

Figura 4. El profesor José María Blázquez con estudiantes universitarios en 1971 (foto Alicia M. Canto).

completa, resaltan más las ausencias que quienes dejaron su firma, sobre todo por las intensas relaciones epistolares mantenidas por George E. Bonsor (Maier Allende 1999b) y sus contactos con el mundo del coleccionismo extranjero. No hemos encontrado, por ejemplo, la firma de Arthur Byne ni de su esposa, Mildred Stapley. Los Byne, estudiosos de la historia del arte y la arquitectura en España, fueron comisionados por Huntington para adquirir también obras en su nombre antes de entrar a trabajar para Williams Randolph Hearst (Merino de Cáceres y Martínez Ruiz 2012: 267 s.). Durante ese tiempo tuvieron un sueldo específico para ello y al poco adquirieron el estatuto de conservadores de la Hispanic Society of America. Cuando Arthur Byne llegó a España en 1915, George E. Bonsor llevaba ya años comerciando con Huntington, resulta plausible pensar que el recién llegado se hubiese acercado a visitar NRC, pero no fue así o, al menos, no hemos hallado constancia de ello.

Con respecto de los investigadores y arqueólogos del momento, pensamos que la NRC gozó de la consideración de yacimiento científicamente casi agotado, lo que le confirió un carácter marginal como lugar de interés para la investigación arqueológica. Además, a partir de la década de los sesenta, se producirá una eclosión de nuevas excavaciones y yacimientos visitables que fomentarán esa marginalidad, a pesar de la excavación del anfiteatro, hasta que a mediados de la década de los setenta sea objeto de una nueva interpretación. No obstante, sí parece, cuanto 
menos curioso, que no haya quedado ningún registro, ni firma ni en otro soporte, de Antonio Blanco Freijeiro, quien fue catedrático de Arqueología en la Universidad de Sevilla durante casi veinte años, así como de la numerosa escuela que formó en esa sede, sobre todo porque la NRC fue objeto de atención por algunos miembros de este grupo ([Luzón Nogué y León Alonso] 1996).

\section{LA VISITA TURÍSTICA EN LA NRC}

Con todo, expertos, personalidades, diletantes o integrantes del "mundo de la cultura", suponen un porcentaje mínimo de los visitantes: el público mayoritario ha estado compuesto por desconocidos viajeros y turistas que han accedido a la NRC desde su apertura. La parquedad de la información directa impide analizar procedencias, medios de conocimiento acerca de la NRC o las motivaciones de la visita. Por el contrario, otras fuentes indirectas nos acercan a aspectos desconocidos del turismo en la NRC como la constatación, a través de las anotaciones, de los ingredientes del turismo cultural típico: la complementación de la visita monumental y artística con el interés gastronómico. En 1894 encontramos un grupo de ocho personas, que deja este mensaje: "En 24 de Abril de 1894 visitamos este museo cuyo recuerdo no se borrará de nosotros, y el cual abandonamos impulsados por el aromático e invitante aroma de unos pollos con arroz".

Hasta prácticamente la década de los sesenta del siglo $\mathrm{xx}$, resulta imposible distinguir del núcleo de visitantes nacionales quiénes proceden de otras provincias distintas a Sevilla, salvo en contadas ocasiones. El único colectivo al que propiamente puede calificarse como turista es al extranjero por su mayor regularidad en la indicación de los lugares de origen.

Ya desde el comienzo de la NRC, la figura de Bonsor sirvió como vehículo de atracción de la comunidad británica residente en Sevilla cuyos miembros aparecen con cierta frecuencia por la NRC, sobre todo la familia del médico John S. Langdon. Este sentido de comunidad aparece muy reforzado por la presencia de personas con funciones de cohesión religiosa (1889, en una visita de un grupo de seis personas de esta comunidad uno firma como "British Champelain of Seville"), pero también por la introducción de costumbres británicas desconocidas hasta entonces en España, como la práctica del fútbol, en la que Johnston, McDougall (también habituales visitantes que habían sido invitados a la inauguración en 1885) y Langdon desempeñaron un papel fundamental (Castro Prieto 2012).
Las figuras 5a y 5b muestran que el turismo extranjero a lo largo del siglo XIX fue minoritario, con números que no llegan al medio centenar anual, salvo picos anómalos. Los países de procedencia durante este periodo son principalmente Reino Unido, Francia, Países Bajos, EEUU, Noruega, Argentina y Dinamarca. Si bien no puede hablarse de ninguna estacionalidad concreta, se observa una concentración en los meses de primavera. Los visitantes suelen acceder en pequeños grupos de tres o cuatro personas, pero tampoco son infrecuentes los individuos que vienen solos.

El relato simulado de la visita de un inglés a Carmona, aparecido en La Revista el 19 de febrero de

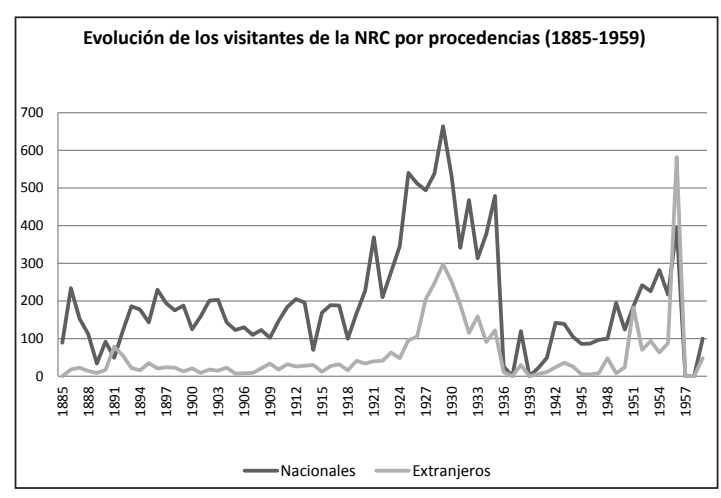

Figura 5a. Evolución de visitantes por procedencias (18851959).

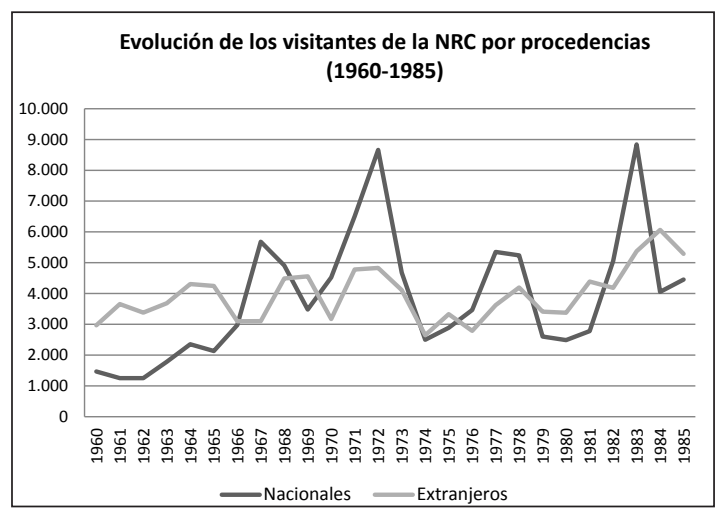

Figura 5b. Evolución de visitantes por procedencias (19601985).

1888, bajo el título "Carmona por dentro", muestra, con el tono de parodia que usaron como recurso habitual los regeneracionistas, el comportamiento que podríamos calificar como típico del viajero del momento. Se trata de un hombre que viaja solo, que durante dos días se dedica a ver todo lo que puede, que anota cualquier dato que le llama la atención y 
que demanda de los lugareños cierta labor de guía e intérprete. El blanco de las críticas del articulista no era la ausencia de infraestructuras adecuadas (accesos, posadas, casas de comidas o indicaciones), ni el uso del turismo como fuente de ingresos (no cuestiona el pago por entrar en la Necrópolis Romana frente al acceso libre de iglesias u otros monumentos como el alcázar), sino la incultura generalizada del pueblo. Una ignorancia que lleva a explicaciones estrambóticas y fantasiosas que decepcionan al visitante, "que anota lo que ve, pero no lo que oye".

La denominada por entonces "industria de los forasteros" generó, como en el resto del país, ciertas expectativas económicas en torno a la NRC, al menos en determinados personajes que, como José Lasso de la Vega o José Vega Peláez, frecuentaron la NRC quizás como guías. El primero de ellos dejó esta indicativa anotación en 1898: "Aquí estuvieron ( sic por estuvo) la colonia Montañesa, el día 17 de mayo, vieron mucho, tomaron agua... y fuesen y no dejaron nada".

En los primeros años del siglo xx, la acción estatal se deja sentir en el fenómeno turístico con desigual acierto (González Morales 2005). Hecho que quizás no se note tanto en la NRC por una mayor afluencia de visitantes cuanto por la aparición de profesionales vinculados al sector. Algunos visitantes firman como intérpretes, incluso como "intérprete del Hotel de Madrid" o "guía de Viajes Marsans", agencia española fundada en 1910, lo que denota la integración de la NRC en los circuitos turísticos del momento, cuyo componente monumental fue esencial.

En fechas inmediatas a la Exposición de 1929 celebrada en Sevilla se advierte una afluencia sin precedentes de personas procedentes de Iberoamérica que, en bastantes ocasiones, resultan ser políticos o embajadores con sus cortejos de acompañantes. Después la visita caerá en la década de los treinta y cuarenta debido a la guerra civil y las políticas aislacionistas del régimen de Franco, para remontar en los sesenta con el auge del turismo de masas y la estandarización de los grupos comerciales. En esos años se amplía el listado de países de procedencia, aunque los más habituales continúan siendo de Europa occidental, a los que se une Italia, cuyos nacionales apenas habían estado en la NRC con anterioridad.

Uno de los aspectos más llamativos asociados a la visita turística es la necesidad de explicación de los vestigios visitables, a pesar de los excepcionales medios de exposición con que contaba el yacimiento y el museo desde casi sus inicios. En efecto, tanto uno como otro disponían de rótulos identificativos. Incluso se había acondicionado la tumba 118 para dar una idea de las pinturas funerarias enfoscando y pintando la cámara a modo de réplica del original. La obra de De la Rada y Delgado, al igual que un catálogo del que no disponemos de ningún ejemplar, eran asequibles en el museo, aunque parece que no se vendieron más de una docena, entre ambos, en más de veinticinco años de contabilidad ${ }^{20}$. Pero a pesar de todas estas facilidades, el recurso fundamental ha sido la explicación de viva voz durante la visita. Esta forma de acercamiento al público ha estado presente desde el principio, ya que el acto fundamental en la inauguración fue un gira explicativa, fórmula repetida al año siguiente ([Fernández López y Bonsor] 1889).

En esos casos, esta práctica respondía al supuesto mayor conocimiento que tenían los propietarios de la NRC sobre el resto de visitantes invitados, aunque los especialistas discrepasen más tarde de sus interpretaciones (Rada y Delgado 1885: 99-100) o de la ordenación de los objetos en el museo (Sales y Ferré 1887: 103). Pero salvando el ojo experto de unos pocos, para el resto del público el uso de guías es la forma más amena, cómoda y fácil de compensar la dificultad de intelección de lo que se está viendo y la ausencia de conocimientos sobre mundo funerario romano. Miembros de la Sociedad Arqueológica de Carmona y otras personas cercanas a los propietarios, cuyas firmas aparecen de forma frecuente en los álbumes, podrían haber desempeñado ese papel. No obstante, esta función estuvo ejercida por vigilantes o conserjes, de la que además se extraía un complemento económico. Ya Bonsor en carta dirigida a José Ramón Mélida (Maier Allende 1999b: 103) advertía de que esa función había sido asignada a los vigilantes como complemento a la mera guardia.

Desde los comienzos, la NRC contó con guardias que cobraban la entrada en un régimen laboral desconocido. Luis Reyes, el trabajador más antiguo de las excavaciones, posiblemente fuese uno de ellos, si no el primero. Sin embargo, el mejor conocido es Fernando Ortiz Escamilla, que empezó a desempeñar esta función a comienzos de la segunda década del siglo xx. Ortiz Escamilla adquirió fama por pasar de ser prácticamente analfabeto a un "erudito orador que asombra con sus explicaciones a los visitantes", en opinión del Ayuntamiento de Carmona en el escrito por el que se unía a la petición de la Comisión de Monumentos para que se le concediese la Medalla al Mérito en el Trabajo, en 1960. Debe reconocérsele un interés autodidacta porque la única preocupación de Juan Lafita, que fuera su jefe directo durante más de veinte años, hacia él era que le otorgasen la condición de guarda forestal para poder llevar

\footnotetext{
${ }^{20}$ La guía de De la Rada fue sustituida por otra más actualizada (Fernández-Chicarro 1969).
} 
insignia y arma de fuego con la que ahuyentar a quienes se colaban en la NRC para robar almendras. Concepción Fernández-Chicarro, a poco de tomar posesión como directora de la Necrópolis Romana en 1959, pediría al Ministerio de Educación Nacional, del que dependía la institución, la dotación de una plaza de auxiliar porque uno de los graves problemas que advertía era que las visitas eran guiadas por el guarda, cuyas explicaciones "carecían de cualquier rigor científico".

$\mathrm{Su}$ sucesor como vigilante no podía dedicarse a guiar visitas ya que este puesto lo tenía como segunda actividad, pero sus hijos sí. Uno de ello, a comienzo de los sesenta, acaparó cientos de comentarios en varios idiomas en los álbumes de firmas, en agradecimiento por sus instructivas explicaciones. El hecho de que el jeune guide de muchas de estas anotaciones ejerciese esa labor de intérprete entre los siete y los diez años no parecía importar mucho. Tampoco que lo hiciese solo con una retahíla de ideas reelaboradas a partir de los retazos de las que ofrecían Juan de Mata Carriazo o Concepción Fernández Chicarro a los visitantes universitarios o distinguidos a los que atendían y, por supuesto, en un español aderezado con algunas expresiones comunes en otros idiomas extranjeros. Lo cual da idea cabal del fenómeno turístico y el interés por la visita cultural en esa época. La rigurosidad no era tan importante como la disponibilidad de un recurso ameno, simpático y liviano, que colmase la expectativa de salir de la NRC con una idea ligera del interés de lo que se había visto durante la hora y media anterior. Por supuesto, sin que se preguntaran qué hacía un niño de esa edad en un yacimiento en lugar de estar en el colegio, lo que en sus países de procedencia podría ser considerado como causa de un grave escándalo. Se asumía como normal una situación que ya para entonces, incluso en el contexto español, resultaba ciertamente anormal, con esa superioridad, indiferencia y ausencia de crítica que caracterizan la mirada turística.

Las explicaciones ofrecidas por este chico no solo colmaban las expectativas de turistas ávidos de cualquier información, sino de también un público que prima facie podría pensarse que sería más exigente. A finales de abril de 1960, una visitante, Khaty Stillis, deja anotado un comentario en forma de queja sobre el joven guía. "A change in guide would improve the atmosphere!". Poco podría imaginar que al día siguiente serían Marguerite Yourcenar y Gracie Frick quienes defendiesen al chico. "A stupid comment, Miss Willis (sic por Stillis). No. Our little guide was good. Grace Frick (the same, says the guardian). Le petit garçon qui nous a servi de guide était excellent. Marguerite Yourcenar" (Fig. 6).

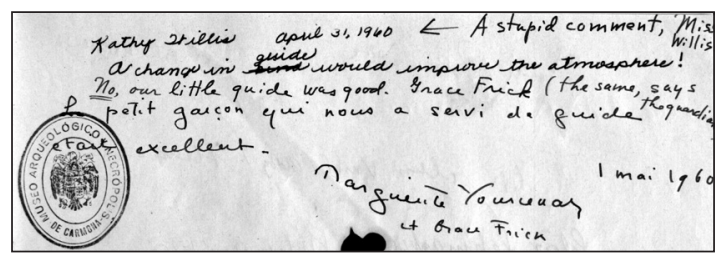

Figura 6. Anotaciones de K. Stillis, G. Frick y M. Yourcenar.

A esta familia le sucedió la de su hermano que ya había realizado funciones de guía durante los fines de semana, con lo cual la situación siguió tal cual. El traspaso de la Administración General del Estado a la Junta de Andalucía de la NRC no modificó tampoco el acompañamiento guiado de los visitantes por parte de los vigilantes. Sin embargo, la mayor disponibilidad de medios para la interpretación junto con la asunción de estándares más exigentes en la interpretación del patrimonio cultural, han introducido importantes cambios en esta práctica que, en la actualidad, recae sobre el personal técnico y directivo de la institución o sobre profesionales de la interpretación patrimonial.

\section{LA NECRÓPOLIS ROMANA DE CARMONA Y EL AULA}

La finalidad educativa de los museos es una característica ínsita de estas instituciones prácticamente desde sus orígenes como establecimientos abiertos al público, a partir de la segunda mitad del siglo XVIII. Otro tanto puede decirse de los precoces yacimientos visitables. Fuera de nuestras fronteras existen actuaciones similares a la de la NRC, aunque cada una de ellas presente variantes específicas. Por ejemplo, en Cranborne Chase (Dorset, Inglaterra), Pitt-Rivers excavó una serie de complejos prehistóricos que singularizaban ese paisaje, disponiendo los objetos recuperados y algunos otros de carácter etnológico en museos locales con un ánimo decididamente pedagógico (Bowden 1991: 141-150).

Sin embargo, la relación entre los museos y las aulas apenas si se materializará a lo largo del todo el siglo XIX debido más a la incapacidad y desinterés de la educación reglada que a la reticencia de los museos.

En España, el tiempo en que se inaugura y da sus primeros pasos la NRC está marcado por una aguda contradicción, en lo referente a la escuela y a la educación reglada en general. Frente a desarrollos teóricos y prácticos vanguardistas, pero de alcance muy limitado, se abre una práctica sumida en el caos, la incapacidad y la ausencia de medios materiales y humanos, aderezado todo ello de altas dosis de 
abandono e incompetencia política. Ambos extremos tienen fiel reflejo en la NRC.

Las apetencias de limitar la libertad de cátedra del primer gobierno canovista provocaron la renuncia o apartamiento de un pequeño, pero muy activo, grupo de catedráticos de universidades e institutos, cuya respuesta al ambiente represivo de la Restauración fue la creación de la Institución Libre de Enseñanza. Sus impulsores, muy influidos por el krausismo, pensaron inicialmente dedicarse a la enseñanza superior, pero a poco de comenzar, la Institución se orientó hacia la enseñanza primaria y el parvulario (Morales Moya 1984: 86-87). Dentro del ideario pedagógico institucionalista, desarrollado sobre todo por Manuel Bartolomé Cossío, el excursionismo como actividad física y educación moral tuvo un peso importante en el ámbito educativo escolar (Otero Urtaza 1994: 144 ss.). Pero junto a esta modalidad de excursionismo escolar, profesores y alumnos de la Institución Libre de Enseñanza practicaron el viaje de estudios como medio para estar en contacto con la realidad europea y nacional, para abrirse también a la comprensión de la geografía y de la historia, asociadas indisolublemente en la configuración de los territorios. Estos viajes de estudio, de ocho a diez días de duración media, se preparaban con detenimiento y esmero, prestando atención a los lugares que debían ser visitados por diversos motivos, entre ellos su carácter monumental.

En una de esas austeras y documentadas escapadas, Giner de los Ríos y Manuel Bartolomé Cossío estuvieron en la NRC, concretamente el 31 de mayo de 1888. Aunque aparecen ellos dos solos como únicos visitantes de ese día, no cuesta trabajo suponer que fuesen Sales y Ferré o Sánchez Dalp, ambos habituales de la NRC, quienes les indicasen la existencia de este nuevo punto de interés en las proximidades de Sevilla. Los cuatro habían hecho un viaje juntos por Europa el año anterior (Morales Moya 1984: 91). En el papel fundamental otorgado al estudio de la historia dentro del proyecto regeneracionista plasmado en la obra de Rafael Altamira, muy influido por los postulados institucionalistas, la visita, el conocimiento de los objetos reales, de las excavaciones arqueológicas como contrapunto necesario a las fuentes clásicas, supone no ya un complemento sino las bases mismas de la renovación del conocimiento sobre la antigüedad (Altamira 1997 [1891]: 227 ss.).

La idea de movilidad formativa que comportaba el espíritu institucionalista fue llevado a la práctica - como se ha visto- por el Ateneo y Sociedad de Excursiones de Sevilla. Mas al ser muchos de sus miembros profesores universitarios se trasladó al aula este sentimiento, como complemento práctico de la asignatura teórica. Carlos Cañal, Feliciano Candau, Joaquín Hazañas y la Rúa, Joaquín Romero Murube, Francisco Murillo, Diego Ángulo Íñiguez, tanto de estudiante de Filosofía y Letras como ya de profesor, fueron asiduos guías de visitas universitarias.

Estas visitas se circunscriben a los alumnos de asignaturas, como Geografía Histórica, Historia Universal o Historia de España, de la carrera de Filosofía y Letras; del resto de licenciaturas no se registran visitas, aunque la NRC sea frecuentada por profesores y catedráticos de ciencias naturales o los responsables del Museo de Geología de la Universidad Hispalense.

Tras el bache de visitas de la guerra civil, a finales de los cuarenta vuelven las visitas universitarias, ahora de la mano de Juan de Mata Carriazo, Hernández Díaz, Sancho Corbacho, Collantes de Terán, Concepción Fernández Chicarro que también tuvo un encargo de curso, o de Antonio de la Banda y Vargas, prolongándose estas visitas periódicas a los largo de los cincuenta y sesenta. En esos años se amplía el elenco de centros universitarios registrados, que ya proceden de toda Andalucía (universidades de Granada y Málaga), así como del resto de España: Central de Madrid, Barcelona, etcétera y no solo con alumnos de Filosofía y Letras sino también de otras carreras como Arquitectura. En estos casos se trata sobre todo de viajes de fin de curso y no visitas específicas a la NRC.

La otra cara de la moneda corresponde a las escuelas, es decir las enseñanzas primaria y secundaria. No es este lugar para dar cuenta de los males que aquejaron a la escuela española durante el siglo XIX, baste señalar que en la provincia de Sevilla — como en el resto de España, por otra parte- la situación era desastrosa en medios humanos y materiales, con un alto número de absentismo escolar, aunque la educación infantil era obligatoria a partir de la promulgación de la Ley Moyano en 1857, y por tanto de analfabetismo. Las bienintencionadas propuestas reformistas de la Institución Libre de Enseñanza tuvieron un moderadísimo eco en algunas élites implicadas en la enseñanza infantil ${ }^{21}$, pero con escaso impacto en la práctica diaria de las escuelas tanto en Sevilla capital, como en su provincia. El objetivo básico de las escuelas era ofrecer unos mínimos rudimentos alfabetizadores y un especial empeño en el adoctrinamiento moral católico. El resto de las asignaturas eran consideradas como adornos, convenientes pero no imprescindibles (Montero Pedrera 2006). El panorama para los institutos de Segunda Enseñanza y sus

\footnotetext{
${ }^{21}$ Hecho constatable al leer textos y documentos sobre la enseñanza de la época (Corts Giner y Calderón España [coords] 2008).
} 
centros asociados en la provincia, entre ellos el de San Teodomiro en Carmona, propiedad de los hermanos Fernández López, era ciertamente más exigente con los programas educativos ya que fueron muy valorados por la mesocracia liberal. Sin embargo, aunque en los planes de estudio consultados existían asignaturas relativas a la historia de España, no estaba en su ánimo el excursionismo o salir de las aulas para cotejar en el entorno lo que se aprendía en ellas (Real Apolo y Calderón España 2006).

Con estos mimbres no resulta extraño que hasta 1906 no se apunten los primeros indicios de personas cuya visita esté relacionada con el ámbito escolar. Se trata de los salesianos de Sevilla y Málaga, pero no hay constancia de que estuviesen acompañados de sus alumnos. No obstante, la presencia en dos ocasiones ese mismo año vincula plausiblemente su visita con finalidades ligadas a la escuela del S. Sacramento, donde se impartía Enseñanza Primaria y Secundaria obligatorias, fundada en 1897 en Carmona, diecisiete años más tarde de la fundación de la primera escuela salesiana en España, ubicada en la cercana localidad de Utrera (Rodríguez Villacorta 2006: 250). En 1913 firma un grupo de responsables salesianos tanto a escala nacional, el Superior y el ecónomo, como de Andalucía y Carmona. Dada la composición del grupo pensamos que estamos ante una visita cultural a la NRC en el marco de una gira oficial al colegio salesiano de Carmona.

También en 1904 se produce la primera visita de la Escuela Normal de Sevilla. Los centros normalistas habían vivido desde su fundación, a mediados del siglo xIx, bajo unas coordenadas poco propicias a cualquier cambio en la metodología de la enseñanza, a pesar de las habituales reformas de que fueron objeto sus planes de estudio. La escasa dotación económica, su origen y base popular y la falta de demanda social de instrucción, marcaron su desarrollo en la segunda mitad del ochocientos, aunque paulatinamente se potenciaron otros medios educativos, como las excursiones, las visitas monumentales o los certámenes (Ávila Fernández y Holgado Barroso 2006: 134-136).

En 1918 firma Isabel Ovín Camps, primera mujer en licenciarse en Ciencias Químicas en España, aunque ejerció de maestra en Carmona en una especie de academia que suplía la ausencia de instituto de Bachillerato en la localidad, pero tampoco consta que llevase a los alumnos. La primera evidencia de una visita escolar compuesta por profesores y alumnos es de 1928, del colegio del Ave María (“Alumnos del Ave María visitaron esta Necrópolis Romana el 23 de enero 928"), a pesar de que su fundador Andrés Manjón rechazaba de plano el ideario ins-

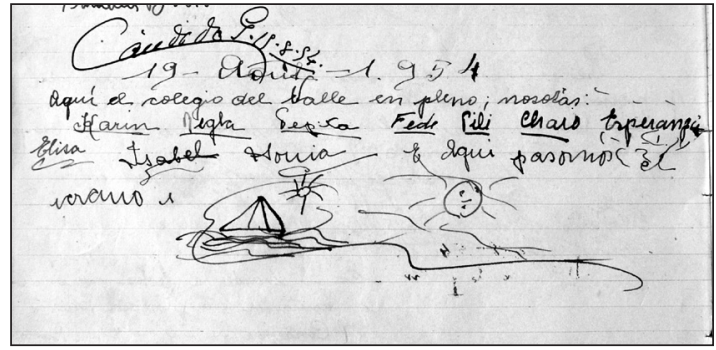

Figura 7. Firma de las alumnas del Colegio del Valle (de Sevilla) en visita realizada en 1954

titucionalista por contrario a la fe católica (Canes Garrido 1999) ${ }^{22}$.

A partir de los años treinta se normaliza la visita de alumnos de diversos centros escolares, entre ellos de Carmona. El tenor de las anotaciones refleja la asimilación de la excursión escolar como complemento educativo de las asignaturas impartidas en las aulas: "En la visita que hicieron a esta Necrópolis Romana, los alumnos de Historia de España del Centro Educativo Carmonense, el día 16 de Octubre de 1932, estamparon su firma en este libro de visitas, como testimonio de la admiración que les ha producido esta joya monumental". O "El sábado 24 de diciembre de 1934 visitaron esta Necrópolis alumnos del colegio del Sagrado Corazón de María de la ciudad de Sevilla, admiraron los restos de aquellos preclaros genios y no genios romanos que alumbraron con sus sapiencias y desaciertos toda la invicta vega de Carmona y aquí queda estampada esta reseña de la visita que es firmada en el nombre de todos ellos por (...)".

Tras la guerra civil, las visitas escolares vuelven a estar presentes desde 1942, incrementándose de forma paulatina con el paso del tiempo. A partir de los cincuenta son muy numerosas, las firmas del propio alumnado llenan muchas páginas de los álbumes, incluso dejan comentarios (u ocurrencias, del tipo "mens sana in corpore sano") relativos más a la impresión causada por el propio viaje u otros aspectos personales, que a los vestigios que han visto (Fig. 7). Si se hiciese una tabla de qué centro escolar ha dejado más constancias de su visita, el palmarés habría que

\footnotetext{
${ }^{22}$ A pesar de haber tardado veintisiete años en visitar la NRC, la relación entre la necrópolis y las escuelas del Ave María habían comenzado en 1901, cuando Sr. Vélez-Bracho, miembro de la SAC, dio cuenta en la reunión ordinaria de la misma, celebrada el 11 de abril de 1901, del impacto que le causó la conferencia impartida por el padre Manjón en la apertura del curso en la Universidad de Granada, trayendo para la biblioteca de la SAC algunos folletos de la mencionada institución escolar. La SAC, por su parte, decidió mandarle algunos ejemplares de sus publicaciones ("Libro de actas de la Sociedad Arqueológica de Carmona. 1893-1909", ACAC III.2.1. Leg. 2, lib. 7., fols. 47v y 48).
} 
otorgarlo al Instituto San Isidoro de Sevilla, que en las décadas de los cincuenta y sesenta visitó anualmente con los cursos más avanzados del Bachiller elemental.

\section{LA IMAGEN DE LA NECRÓPOLIS ROMANA DE CARMONA EN LOS VISITANTES}

El contenido de los dos comentarios escolares anteriores, con el tono reverencial hacia la antigüedad y el carácter monumental de la NRC, permite introducir este último aparatado dedicado a la idea de los visitantes sobre este yacimiento y, a partir de ahí, sobre el patrimonio arqueológico. Este tipo de indagaciones sobre la imagen popular de la arqueología, tan de boga en la actualidad de mano de la arqueología pública (Almansa Sánchez 2006), no pueden hacerse con carácter retrospectivo, habida cuenta de las técnicas demoscópicas de investigación. Por ello los álbumes de firmas y sus comentarios suponen una fuente valiosa y casi única para abordar esta temática en épocas ya pasadas.

Antes de analizar cualitativamente los asientos dejados por los visitantes, debe tenerse presente la naturaleza de estos testimonios. Aunque firmar en el álbum haya sido casi una obligación de cortesía durante mucho tiempo en la NRC, dejar un comentario no. Pero tampoco ha obedecido siempre a un mero acto volitivo, en ocasiones fue parte del protocolo de una visita formal. Con lo cual resulta útil diferenciar aquellos comentarios escritos como producto de una situación de compromiso, de aquellos otros que corresponden a un deseo espontáneo de quien lo hace. Las situaciones formales usualmente dejan otras huellas: identificación de la persona que firma con señalamiento expreso del cargo que ocupa o título que ostenta, la firma de otras personas que la acompañan, ya sean familiares ya colaboradores de menor rango, o alguna introducción o presentación escrita por el responsable en ese momento de la NRC.

Si se excluye la mera anotación de la fecha o el lugar de procedencia, ya que no ofrece información a los efectos que ahora nos interesan, se contabilizan 696 anotaciones, si bien casi la mitad son agradecimientos al joven guía de la década de los sesenta. Otros muchos tienen un contenido meramente denotativo de la presencia en la NRC en tal fecha, usando fórmulas como "En recuerdo de nuestra visita a la Necrópolis Romana de Carmona" o similares. Práctica que se hace bastante común a partir de la década de los cincuenta. Por contra, otras anotaciones presentan un valor connotativo que expresa algún sentimiento o idea sobre lo visto o inspirado en ello, o bien sin relación alguna con la NRC. Estos últimos, entre los clasificables como espontáneos, son los de mayor interés ahora.

Las muestras de anotaciones formales suelen ser más frecuentes en los treinta primeros años de vida de la NRC, cuando los propietarios estaban aún vivos y posiblemente recibían o acompañaban a los ilustres visitantes que dejaron esas muestras de reconocimiento, por lo que existen alusiones a ellos. Así, por ejemplo, Francisco de Asís de Vera, de la Real Academia de San Fernando, en visita realizada en 1892 escribe: "Felicito a los Srs. D. Jorge Bonsor y D. Juan Fernández López, por este patriótico descubrimiento de la Necrópolis". Carlos Cañal en 1893, "Apliquen su actividad todos los que en Carmona se dedican a los estudios arqueológicos y con poco más que se descubra lograran mostrar al mundo la historia del hombre en nuestra España”. José Lasso de la Vega, congresista de origen local, el 20 de marzo de 1896 anota: "iGloria a los descubridores de la Necrópolis Romana. La posteridad les deberá gratitud!”. En 1902, Vicente Blasco Ibáñez, también deja constancia de su admiración por la obra de Fernández López y Bonsor, "Admiro el entusiasmo y la fuerza de voluntad de los descubridores de la Necrópolis de Carmona". Incluso también en este tipo de reconocimientos, se advierte el olvido de la figura de Fernández López, Lucas Mallada de la Comisión del Mapa Geológico de España, anota en 1905 "Merece bien de la Patria y de la ciencia el ilustre Extranjero (sic por extranjero) que descubrió y ordenó las riquezas arqueológicas de esta Necrópolis". Años más tarde, en 1926, un visitante de firma ilegible deja "Felicito al señor Bonsor por la preciadísima labor patriótica de reconstrucción arqueológica que con singular acierto ha llevado a cabo". Bien cierto es que en esta segunda fecha, Fernández López había muerto el año anterior y George E. Bonsor estaba en un momento de máximo reconocimiento social, al año siguiente lo honrarían con el nombramiento como hijo adoptivo de Carmona, aunque hacía casi veinte años que ya no vivía en la localidad.

Junto a esos reconocimientos de los propietarios y excavadores, un amplio elenco de anotaciones, tanto formales como espontáneas, deja constancia de una idea de la arqueología y la antigüedad como temas solemnes que descubren sorprendentes maravillas dignas de admiración, pero sin conexión alguna con la actualidad: los yacimientos monumentales son joyas que adornan la historia patria. Lógicamente están dejados por nacionales españoles y, dentro de los formales, es el tono más común hasta los años cincuenta. Sin embargo, no creemos que ello soporte la relación entre turismo y nacionalismo, en el sentido de que este haya sido el motor del interés de la visita 
monumental por parte de los turistas (Díaz-Andreu 2014). Fundamentalmente porque, aun cuando el surgimiento de las naciones moviese la aparición de historias nacionales y la valorización de monumentos que la ejemplificaban, como se ha visto en las páginas precedentes, la motivación nacionalista está totalmente ausente en el ideario de los promotores de la NRC, más acorde con el regeneracionismo finisecular. Además, frente a determinadas campañas de excavación patrocinadas por los organismos públicos, como las de Numancia en 1853 y entre 1861 y 1867 , las de la NRC fueron una iniciativa privada, ajenas a la idea de enriquecimiento del acervo cultural español que presidía aquellas (Rivière Gómez 1997).

En cualquier caso, debe tenerse presente que este tipo de anotaciones responden a situaciones protocolarias o formales, donde importa decir algo con relación a las grandes narrativas sociales, sean patrióticas o religiosas, pero no dejan de ser puros recursos retóricos. El tema fúnebre también inspira comentarios escatológicos, sobre todo en personas pertenecientes al clero católico.

Salvo contadas personas que son expertas, en la mayoría de comentarios se observan imprecisiones terminológicas o conceptuales y, en no pocas ocasiones, dificultad para expresar de forma clara las ideas, debido sobre todo a la improvisación del momento de redactar la anotación.

Una persona que se identifica como licenciado en Derecho, en 1895, escribe: "Absorto he contemplado los magníficos ejemplares que han dejado en este sitio las civilizaciones que pasaron del arte en sus diversas manifestaciones; entre ellas y sobre todo, las antiquísimas osamentas de los primitivos individuos de la especie humana, proclaman elocuentemente cómo todo es efímero y pasajero y la inmortalidad e infalibilidad de la existencia de Dios". En 1898 otra persona no identificada deja la siguiente observación: "Los grandes pueblos dejan a su paso grandes obras como huellas". O "Admiro en la Necrópolis Romana el triste fin de la grandeza humana" (1899). Alejandro Leroux, en 1902, deja un mensaje de tono profundamente regeneracionista, "La ciencia regenerará a la sociedad y el arte embellecerá la vida. Ciencia y arte, antiguos y modernos, harán la revolución”. En 1905, el presidente del Ateneo sevillano anota, "El estudio de la arqueología es tan importante que mediante él se rectifican los errores de la Historia". La primera anotación en una lengua extranjera, hace una precisión de carácter arqueológico. En 1896, Edward Spencer Dodgson escribió: "This Roman hill is like an antechamber of the catacombs of Rome, supremely valuable and interesting". Y en 1908, en un asiento, se mezclan todos los temas anteriormente aludidos: "Si alguna vez la Revolución arrojara nuestros huesos de sus sepulcros, cuando duerman a la sombra de la Madre Iglesia, gracias a la Arqueología no perecerán: esta atravesará los siglos llevándolos en sus alas y los guardará en un museo ¡Menos mal!”.

Los comentarios de Tomás Domínguez de Arévalo, conde de Rodezno, y de Martínez Kléiser, periodista y académico sevillano, manifiestan en 1905 una acendrada ideología de corte racial, muy próxima a las que surgirán años después en los totalitarismos europeos, vinculada al pasado manifestado por los restos arqueológicos. Dice el primero: "El descubrimiento del pasado y la investigación histórica proporcionan al hombre dos grandes satisfacciones: una positiva, la verdad, y otra, la ilusión consoladora de ensanchar el pequeño campo en que nos movemos para enlazarlo con la génesis gloriosa de nuestra raza". El segundo, por su parte, anota: "Las razas se perpetúan a través de los tiempos; pero esta perpetuación sólo alcanza de las generaciones el recuerdo. Un pueblo tan fuerte y tan soberano como el de Roma sólo llega hasta nosotros como un sueño del pasado que nos ofrece sus cenizas". Por último en esta serie, reproducimos el comentario de un presbítero en 1941: "Hoy 11 de Noviembre de 1941, mes conmemorativo de los difuntos, visitamos esta Ciudad de muertos recordando en cada tumba su muerte eterna, ya que muchos de ellos ni siquiera guardaron la ley natural. Creo con Santo Tomás que algunos recibirían el bautismo exvoto. Descansen en paz los que vivieron con Dios. Nota: Llovía en fecha ut supra".

Otros comentarios minoritarios en este lapso de tiempo, pero no por ello menos relevantes, reflejan una visión mucho más intrascendente, proyectando una opinión personal sobre lo que ve, o aprovechando la ocasión para dejar alguna ocurrencia sin vinculación alguna con los vestigios. En 1891, una de las primeras anotaciones reza: “ $i \ldots$ Y sobre estas tumbas se ven lozanas las higueras chumbas....!”. Seis años más tarde, leemos: "A los muertos romanos lo mismo les deseo que a los cristianos RIP". En 1898, otro manifiesta "Uno que no ha visto nada, pero se lo supone todo", quizás debido a la dificultad de comprensión de los complejos funerarios. Hubo quienes prefirieron hacerlo en verso (1910): “¡Oh Necrópolis Romana/ Evocadora evidente/ De recuerdos del pasado!/ Un hombre de edad temprana/ Que es poeta y no es creyente,/ Confiesa haberte admirado".

Otras personas dejan también testimonios de sorpresa y admiración desde connotaciones personales. "Me dan ganas de haber sido Romana (sic)", señala una mujer en 1911. Otro, ya en 1920, "Recordando al gran Nerón hay mucho que contemplar en 
este salón que es muy digno de admiración, para saberlo apreciar". En 1925, "La visita es ligera; cada objeto es un misterio, un pretexto para mirar el pasado, acercándonos al hombre trogolodita". Conforme se avanza en el tiempo, los comentarios muestran mayor desafección con respecto de los vestigios visitados. En 1931, un visitante escribe "La Necrópolis me ha dejado un poco triste. Es algo dramático aquello de los ritos funerarios, las plañideras, etc. Yo, un espíritu de hoy que he vivido en Hollyvud ( $\mathrm{sic}$ ) y que prefiero el cabaret al atrio, la manzanilla de Sanlúcar a los perfumes de Roma; que lejos de evocar la espada, pienso en la suprema felicidad de haber nacido en el siglo xxx (sic)". Por último, dos comentarios en 1941 que conectan, no sin ironía, la dura realidad del momento con lo que ve. "Ya no quedan muertos en los hoyos y para los vivos quedan pocos, poquísimos bollos" (Fig. 8). Más escueto, el segundo escribe la fecha bajo su nombre (el 8 de junio de 1941) y añade "Segundo año racionado ¿Quién verá el tercero?’.

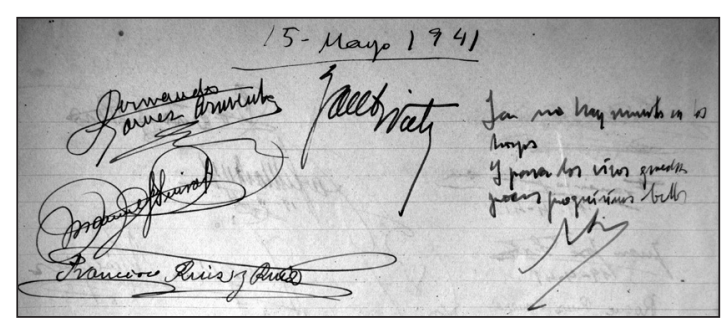

Figura 8. Anotación anónima en el Álbum de firmas

Estos ejemplos, aunque sean una mínima parte de los existentes dan fiel idea de lo expuesto. La distribución de anotaciones en la horquilla cronológica analizada revela un progresivo aumento conforme avanza el tiempo y se expande el hábito de escritura, hecho observable en la mayor soltura generalizada en aspectos caligráficos como la proporción entre las letras o la grafomotricidad de la rúbrica. Pero esta mayor frecuencia de asientos también fue consecuencia de un crecimiento del culto al yo y a los sentimientos personales, aunque fuesen intrascendentes o anecdóticos, frente a lo que hasta entonces era la objetividad incuestionable de la ruina monumental o antigua, ante la cual había que rendir cumplido tributo de admiración o pleitesía para seguir el comportamiento socialmente sancionado.

La distribución de anotaciones de contenido evocador hacia la arqueología o los monumentos como glorias de la patria son más frecuentes entre finales del siglo XIX y los primeros decenios del XX, reflejando cómo ha calado en estas burguesías cultivadas que acceden a la NRC tanto un vago sentido regeneracionista, como sobre todo la forma en que se les había explicado la historia, en la cual los vestigios arqueológicos eran meros adornos en un relato historiográfico vinculado a la génesis de España como nación, su conexión con el nacionalismo nos parece indudable, pero laxa.

Por otra parte, la casi total ausencia de este tipo de rememoraciones en los cuarenta y su práctica desaparición a partir de los cincuenta, sustituidos por visiones más personales o, sobre todo, anotaciones que pretenden exclusivamente dejar constancia de la visita, contrasta con la ideología dominante y su empeño en las ideas de patria y un reforzado nacionalismo de corte étnico, lo cual revela la poca impregnación social de la que gozaron, más allá de las élites administrativas o algunos profesionales de la arqueología.

\section{CONCLUSIONES}

A modo de apretada conclusión, solo cabe resaltar la importancia y validez de estos documentos, generalmente despreciados en los estudios históricos por su autoría difusa, como fuentes esenciales para el estudio de la gestión de espacios patrimoniales.

De la explotación de estos datos debe destacarse el amplio impacto que tuvo, desde sus orígenes, la NRC en el ámbito cultural sevillano, sobre todo en aquellas personas interesadas por la historia y la arqueología, normalmente vinculadas a la Universidad o a asociaciones culturales (el Ateneo y Sociedad de Excursiones de Sevilla), pero no así en el resto de la mesocracia burguesa tanto capitalina como de la provincia.

Llama poderosamente la atención la tardía incorporación de los escolares en la visita a la NRC, pese a la llamada a las visitas patrimoniales que se estaba haciendo desde los círculos institucionalistas, lo que permite deducir que su eco fue más bien tardío en el ámbito escolar español, al menos en este aspecto.

Además, se observa un importante cambio entre los visitantes en la década de los sesenta, cuando la visita se masifica al tiempo que se "democratiza", lo cual se manifiesta en la pérdida de interés por parte de los visitantes, quienes hacen gala de un grado de conocimiento y sensibilidad menor que los de años anteriores. Así, estos se muestran ávidos de ver y no de saber, un conocimiento que sí demandaban los primeros visitantes de la NRC. Además, este menoscabo se observa en la simplificación y empobrecimiento de la imagen que se tiene sobre la Necrópolis Romana de Carmona. 


\section{BIBLIOGRAFÍA ${ }^{23}$}

Álamo Martínez, C. del 2009: "Las excavaciones de Archer M. Huntington en Itálica", El Tesoro Arqueológico de la Hispanic Society of America, Sevilla, 152-169.

Almansa Sánchez, J. 2006: "La imagen popular de la arqueología en Madrid”, Arqueoweb 8(1). http:// www.ucm.es/info/arqueoweb/numero8_1/conjunto8_1.htm

Altamira y Crevea, R. 1997 [1891]: La enseñanza de la Historia (edición de Rafael Asín Vergara), Madrid.

Ávila Fernández, A. y Holgado Barroso, J. 2006: “La formación inicial y permanente del magisterio primario en Andalucía durante los siglos XIX y XX", M. I. Corts Giner y M. C. Calderón España (eds.), Estudios de Historia de la Educación Andaluza, Sevilla, 123-190.

Ayarzagüena Sanz, M. y Renero Arrivas, V. 2009: “Fernández López, Juan”, M. Díaz-Andreu, G. Mora Rodríguez y J. Cortadella Morral (eds.): Diccionario Histórico de la Arqueología en España, Madrid, 265.

Beltrán Fortes, J. 2002: “Arqueología sevillana de la segunda mitad del siglo XIX: una práctica erudita y social", M. Belén Deamos y J. Beltrán Fortes (eds.), Arqueología fin de siglo. La arqueología española de la segunda mitad del siglo XIX, I Reunión Andaluza de Historiografía Arqueológica, Sevilla, 11-42.

Beltrán Fortes, J. 2004: "Manuel Sales y Ferré”, M. Ayarzagüena Sanz y G. Mora Rodríguez (eds.), Pioneros de la arqueología en España. Del siglo XVI a 1912, Zona Arqueológica 3, Madrid, 215-223.

Bendala Galán, M. 1976: La necrópolis romana de Carmona (Sevilla), Sevilla.

Bonsor, G. E. 1931: An Archeological Sketch-book of the Roman Necropolis al Carmona, New York.

Bowden, M. 1991: Pitt Rivers: The life and archaeological work of Lieutenant General Augustus Henry Lane Fox Pitt Rivers, Cambridge.

Canes Garrido, F. 1999: “Las Escuelas del Ave María: una institución renovadora de finales del siglo XIX en España", Revista Complutense de Educación 10.2, 149-166.

Castañeda Alañón, L. 2001-2002: “¿Usuarios o visitantes?", Museo: Revista de la Asociación Profesional de Museólogos de España 6-7, 197-199.

Castro Prieto, J. 2012: El origen del fútbol sevillano. La olvidada memoria británica, Sevilla.

\footnotetext{
${ }^{23}$ Los nombres entre corchetes indican atribuciones de autoría contrastadas por fuentes indirectas, ya que los originales no están firmados.
}

Corts Giner, M. I. y Calderón España, M. C. (coords.) 2008: Estudios de Historia de la Educación Andaluza: Textos y Documentos (siglos XVIII, XIX y XX), Sevilla.

Cruces Blanco, E. (dir.) 1991: Inventario del archivo y biblioteca de Jorge Bonsor, Sevilla.

Díaz-Andreu, M. 2014: "Turismo y Arqueología una mirada histórica a una relación silenciada", Anales de Antropología 48.II, 9-40.

Fernández-Chicarro, C. 1969: Guía del Museo y de la Necrópolis Romana de Carmona (Sevilla), Madrid.

Fernández Gómez, F. y Baceiredo Rodríguez, M. I. 2001: "El pintor Rodríguez Jaldón y la necrópolis de Carmona", A. Caballos Rufino (ed.), Carmona romana, Actas del II Congreso de Historia de Carmona, Sevilla, 71-82.

[Fernández López, J.] 1887: "Reglamento de la Sociedad Arqueológica de Carmona", Memoria de la Sociedad Arqueológica de Carmona, Carmona, 3-19.

[Fernández López, J. y Bonsor, G. E.] 1889: Itinerario de la Necrópolis Romana de Carmona, Sevilla.

Gómez Díaz, A. 2006: "El jardín arqueológico de la Necrópolis Romana de Carmona (Sevilla), 18811930. Un proyecto pionero de acondicionamiento y gestión de un yacimiento arqueológico", J.-P. Morel, J. Tresserras Juan y J. C. Matamala (eds.), The archaeology of crop fields and gardens, Proceedings of the 1st Conference on Crop Fields and Gardens Archaeology, Bari, 283-291.

Gómez Zarzuela, M. 1885: Guía de Sevilla y su provincia para 1885, Sevilla.

González Morales, J. C. 2005: "La Comisión Nacional de Turismo y las primeras iniciativas para el fomento del turismo: la industria de los forasteros (1905-1911)", Estudios Turísticos 163-164, 17-30.

López Rodríguez, J. R. 2010: Historia de los museos de Andalucía. 1500-2000, Sevilla.

[Luzón Nogué, J. M. y León Alonso, P.] 1996: “La figura de Antonio Blanco Freijeiro en el contexto de la arqueología española de su época”, J. M. Luzón Nogué y P. León Alonso (eds.). Antonio Blanco Freijeiro, Opera Minora Selecta, Sevilla, XV-XXIV.

López Rodríguez, R. M. 2010: La Comisión de Monumentos Histórico Artísticos de la provincia de Sevilla, Sevilla.

Maier Allende, J. 1997: "Las Sociedades Arqueológicas en España: La Sociedad Arqueológica de Carmona", G. Mora y M. Díaz-Andreu (eds.), La cristalización del pasado: génesis y desarrollo de la institucionalización de la arqueología en España, Málaga, 303-310.

Maier Allende, J. 1999a: Jorge Bonsor (1855-1930). Un académico correspondiente de la Real Academia de la Historia y la arqueología española, Madrid. 
Maier Allende, J. 1999b: Epistolario de Jorge Bonsor (1886-1930), Madrid.

Maier Allende, J. 2002: “Arqueología sevillana finisecular”, M. Belén Deamos y J. Beltrán Fortes (eds.), Arqueología fin de siglo. La arqueología española de la segunda mitad del siglo XIX, (I Reunión Andaluza de Historiografía Arqueológica), Sevilla, 61-88.

Maier Allende, J. 2004: "El hallazgo de un tesorillo omeya en el cortijo de Santa Clara (Carmona): correspondencia entre Fernández López y Guillemo de Osma y Scull”, Estela, 78-84.

Maier Allende, J. 2009: "Archer M. Huntington, Jorge Bonsor y la arqueología andaluza”, El Tesoro Arqueológico de la Hispanic Society of America, Sevilla, 108-133.

Méndez Bejarano, M. 1989. Diccionario de escritores, maestros y oradores de Sevilla y su provincia (Tres tomos en un solo volumen) (v. o. Sevilla 1922, 1923 y 1925), Sevilla.

Merino de Cáceres, J. M. y Martínez Ruiz, M. J. 2012: La destrucción del patrimonio artístico español. W. R. Hearst: "El gran acaparador”, Madrid.

Mínguez García, M. C.; De la Calle Vaquero, M. y García Hernández, M. 2014: "La visita en el Conjunto Arqueológico de Carmona", I. Rodríguez Temiño (coord.), Investigar, conservar, difundir. El Proyecto Guirnaldas en el Conjunto Arqueológico de Carmona, Sevilla, 141-162.

Morales Moya, A. 1984: "El Viaje en la pedagogía de la Institución Libre de Enseñanza”, Estudios Turísticos 83, 85-99.

Montero Pedrera, A. M. 2006: "Escuela, alumnos y maestros: la aplicación de la Ley Mollano en Sevilla", M. I. Corts Giner y M. C. Calderón España (eds.), Estudios de Historia de la Educación Andaluza, Sevilla, 47-90.

Ortega Cantero, N. 1984: "Conocimiento geográfico y actitud viajera en la Institución Libre de Enseñanza", Estudios Turísticos 83, 69-84.

Otero Urtaza, E. 1994: Manuel Bartolomé Cossío: pensamiento pedagógico y acción educativa, Madrid.

Paris, P. 1910: Promemandes Archéoloques en Espagne, Paris.

Peñalver Simó, M. (coord.) 2010: El Castillo de Mairena del Alcor. El legado de Jorge Bonsor y Dolores Simó, Sevilla.

Rada y Delgado, J. de D. de la, 1885: Necrópolis de Carmona. Memoria escrita en virtud de acuerdo de las Reales Academias de la Historia y de Bellas Artes de San Fernando, Madrid.

Ramírez Olid, J. M. 1999: Osuna durante la Restauración. 1875-1931, Sevilla.
Real Apolo, C. y Calderón España, M. C. 2006: "Los primeros institutos de enseñanza secundaria en Andalucía”, M. I. Corts Giner y M. C. Calderón España (eds.), Estudios de Historia de la Educación Andaluza, Sevilla, 91-122.

Richard, M. O. J. 1889: "Rapport sur découverte de la Necropolis de Carmona (Espagne)", Bulletins de la Société des antiquaires de l'Ouest. 18861888 4, 252-268.

Rivière Gómez, A. 1997: “Arqueólogos y Arqueología en el proceso de construcción del Estado-nacional español (1834-1868)", G. Mora y M. Díaz-Andreu (eds.), La cristalización del pasado: génesis y desarrollo de la institucionalización de la arqueología en España, Málaga, 133-140.

Rodríguez Temiño, I. 2010: "Repensar el concepto de conjunto arqueológico en Andalucía. A propósito del Plan Director del Conjunto Arqueológico de Carmona", V Congreso Internacional sobre Musealización de Yacimientos Arqueológicos. Arqueología, discurso histórico y trayectorias locales, Murcia, 303-316.

Rodríguez Temiño, I. 2014a: "Introducción. El Conjunto Arqueológico de Carmona y el Proyecto Guirnaldas", I. Rodríguez Temiño (coord.), Investigar, conservar, difundir. El Proyecto Guirnaldas en el Conjunto Arqueológico de Carmona, Sevilla, 9-32.

Rodríguez Temiño, I. 2014b: "La actuación de la Comisión de Monumentos de Sevilla en la Puerta de Sevilla en Carmona (1887-1889) a través de la correspondencia de Juan Fernández López: análisis de la administración cultural horonaria", Patrimonio Cultural y Derecho 18, 175-206.

Rodríguez Villacorta, M. Á. 2006: "Primeros pasos de la educación Salesiana en Andalucía”. M. I. Corts Giner y M. C. Calderón España (eds.), Estudios de Historia de la Educación Andaluza, Sevilla, 229-254.

Ruiz Cecilia, J. I.; Rodríguez Temiño, I.; Jiménez Hernández, A. y González Acuña, D. 2011: «A tumba abierta», Una nueva mirada sobre la Necrópolis Romana de Carmona a través de viejas fotografías, Sevilla.

Ruiz Sánchez, J. L. 2009: "El movimiento católico en el arciprestazgo de Carmona. Prensa católica y catolicismo social (1896-1936)", De la Restauración Borbónica a la Guerra Civil (1874-1936), Actas del VI Congreso de Historia de Carmona, Sevilla, 239-268.

Recibido: 20-10-2014

Aceptado: 28-01-2015 